\title{
TRANSFORMATION OF COLLAGEN TO "ELASTIN" IN DERMAL COLLAGENS WITH VARYING SENSITIVITY TOWARDS COLLAGENASE
}

\author{
BY \\ M. K. KEECH* \\ Department of Medicine, University of Leeds
}

(RECEIVED FOR PUBLICATION APRIL 17, 1957)

It has been reported previously (Keech, 1955) that the dermal collagen from eight out of sixty individuals failed to show any evidence of digestion by collagenase under the electron microscope, and that two others reacted excessively for their particular age groups. Indications of variable reactivity towards collagenase were also obtained from nitrogen determinations of the material digested (Keech, 1954a). It was also shown that in one case of dermatomyositis the rash-bearing skin was collagenase-resistant, whereas the abdominal skin from the same case digested normally. All these findings remained unexplained and appeared to be independent of the disease, therapy, and all the experimental procedures.

A small quantity of eight out of the ten abnormally-reacting substrates still remained, so a more detailed electron microscope investigation was undertaken to find out whether the samples shown to be resistant to the action of collagenase would also prove resistant to the action of alkali and periodate which apparently transforms collagen to elastin-like structures (Burton, Hall, Keech, Reed, Saxl, Tunbridge, and Wood, 1955; Hall, Keech, Reed, Saxl, Tunbridge, and Wood, 1955). Microshrinkage temperature experiments were performed as well as analytical studies on the amino acid composition of the various samples. More detailed characterization was accomplished by chromatography and hydroxyproline determinations.

\section{Materials and Methods}

Prepared Collagen.-Six of the eight collagenase-

\footnotetext{
* Empire Rheumatism Council Research Fellow.
}

resistant substrates and the two exhibiting excessive digestion which were used in previous work (Keech, 1955), together with five controls of comparable age showing average collagenase digestion, constituted the starting materials. Each was examined as described below and then treated in one of the following ways:

(a) Suspended in sterile distilled water $\mathrm{pH} 5 \cdot 6$, heated at $37^{\circ} \mathrm{C}$., and samples taken after $1 \frac{1}{2}$, 3 , and $24 \mathrm{hrs}$.

(b) Suspended in $0.2 \mathrm{M}$ potassium hydrogen phthalate buffer, pH 5.0, heated at $37^{\circ} \mathrm{C}$., and samples taken after $1 \frac{1}{2}$ and $3 \mathrm{hrs}$.

(c) Suspended in a mixture of 1 per cent. sodium metaperiodate in phthalate buffer, $\mathrm{pH} 5 \cdot 0$, incubated at $37^{\circ} \mathrm{C}$., and samples taken at $1 \frac{1}{2}$ and $3 \mathrm{hrs}$.

(d) Suspended in $0.2 \mathrm{M}$ borate buffer, $\mathrm{pH} 8.8$, and incubated at $37^{\circ} \mathrm{C}$. for $24 \mathrm{hrs}$.

Antibiotics. $-0.05 \mathrm{ml}$. of a penicillin and streptomycin mixture was added to each test tube in the above experiments. This successfully prevented bacterial contamination.

Samples for Electron Microscopic Examination were ground gently in a glass tissue grinder until a milky suspension was obtained; drops were placed on collodioncovered 200-mesh copper grids, drained with filter paper, allowed to dry, washed with distilled water, shadowed with chromium, and examined in a Siemens electron microscope, type UM $60 \mathrm{C}$.

Counts of the different elastin-like structures were made by carefully scanning two grids from each sample. The specimen holder had been adjusted to visualize 25 squares of the grid, and each part of each square was examined in sequence. As each square was scanned at a magnification of 11,000 and as about 25 fields were needed to cover each square, a minimum of $2 \times 625$ fields were scrutinized from each specimen. 
Attempts were made to obtain approximately the same amount of deposit on all the grids from all the samples, so that valid comparisons could be made. This proved difficult, but the majority of the grids were classified as bearing a "heavy" deposit, and where variations in density affect comparisons in the counts, this has been indicated in both Tables and text.

The above experiments were performed in large batches, treating several different substrates from each group in each of the ways described at the same time. This ensured that exactly the same conditions (chemical solutions, incubation temperature, etc.) appertained to the reactive and resistant materials alike. Again, electron microscope examination of all the experiments on the same substrate were undertaken within 2 to 3 days, for ease of comparison.

Terminology.-The presence of several types of "elastin" in the materials used in this study is somewhat confusing. For clarity they were classified as follows:

(a) Naturally-occurring elastin or fully-formed elastin (Fig. 14) as described previously (Keech, Reed, and Wood, 1956) comprising three variants (skin-type, filamenting, and natural networks) which are found in fresh whole dermis and prepared dermis from all age groups, aorta, tendon, and ox ligamentum nuchae. This appears in the text without quotation marks. The term fully-formed elastin bears no genetic implication, but simply indicates that it is found in all fresh and prepared starting materials.

(b) Morphologically similar structures, seen after a variety of procedures, are referred to as fully-formed "elastin" or elastin-like structures. There is much evidence that these structures resemble the naturallyoccurring elastin described under $(a)$ in chemical properties as well as in morphology (Burton and others, 1955; Hall and others, 1955). However, until this point is fully established, quotation marks are used.

(c) A larger form, composed of a very thick, dense portion splaying out into typical skin-type or filamenting elastin (Figs 26-35). These frequently stretched over several microscopic fields, measured $20-30 \mu$ in length, and formed a distinct group which proved the most sensitive index of a true transformation picture (see below). The term transformation structure (TS) is used for this group, implying that they exhibit one or more of the various morphological characteristics of "elastin". As already reported (Keech and Reed, 1957), large, dense, square-ended fibres are present in all the starting materials of both fresh whole dermis as well as the prepared substrates. As shown in the published illustrations, prolonged heat at or below body temperature gradually converted some of these fibres into TS, their appearance depending on the amount of electron-opaque amorphous material coating the elastin filaments. However, they were found in far greater numbers following the reagents (borate, periodate and phthalate) used in the present study.

A transformation picture (Figs 36 and 37) denotes, therefore, a quantitative and qualitative change in the whole deposit, characterized by:

(i) A smaller amount of collagen, the majority of which showed evidence of degeneration;

(ii) An increase in skin-type "elastin" above that which could be accounted for by heat alone;

(iii) An increase in TS (or in large networks in the substrate from the infant D12: see Table I).

Qualitatively, the appearance of the deposit was quite distinctive, the elastin-like material covering most of the grid in the samples recorded as presenting a marked transformation picture.

The word "transform" is thus used to denote the apparent transformation of collagen to elastin-like structures reported previously (Burton and others, 1955; Keech and Reed, 1957) as well as in the present study. The term "transformation structure" (TS) was first used to describe the conversion of the large, dense fibres present in the starting materials to "elastin" (Keech and Reed, 1957). The same name is now used for the identical structures found in greater numbers in the present investigation. A "transformation picture" (defined above) refers to a change in the whole deposit, the mainly 'collagenous starting material being replaced by elastin-like structures. Part of this change was accomplished by the conversion of the large, dense fibres to TS.

It is important to make it quite clear that the terms defined above are used descriptively and as an aid in classifying the range of structures counted and recorded in Tables I and II. They are not intended to imply any underlying mechanism or biological process.

\section{Results}

The results are summarized in Tables I to III, where Group I comprises substrates exhibiting average collagenase digestion, Group II comprises collagenase-resistant substrates, and Group III comprises those showing excessive digestion by collagenase.

\section{Starting Materials (Figs 1-8)}

These showed marked differences between each group, as well as age differences within Group I, the latter giving the typical pictures of child and adult prepared dermis. In the younger subjects the slightly thinner collagen fibrils were usually found in clumps, mixed with, or partially obscured by, the plentiful amorphous material and dense bits. In contrast, the collagen in a 56-year-old adult was in long, winding bundles of clean fibrils with very little associated amorphous material or dense bits. The substrate from the infant (D12) contained nearly as much filamenting as skin-type elastin (a common finding in very young subjects), whereas filamenting formed only a small fraction of the total 
fully-formed elastin in the rest. In addition many structures were intermediate between the four variants of elastin listed in Table I, but (as has been noted in previous work) the action of heat alone, or heat plus other reagents, rapidly rendered them typical of one particular variant and hence easy to categorize. The 56-year-old dermis (D15) had scanty, long, thick pieces of filamenting elastin which

TABLE I

RESULTS OF VARIOUS TREATMENTS TO PREPARED DERMAL SUBSTRATES WHICH DIFFERED IN SENSITIVITY TOWARDS COLLAGENASE

At Least 1,250 Microscopic Fields were Examined at Each Time-Interval

\section{GROUP I. SUBSTRATES EXHIBITING AVERAGE COLLAGENASE DIGESTION (CONTROL GROUP)}

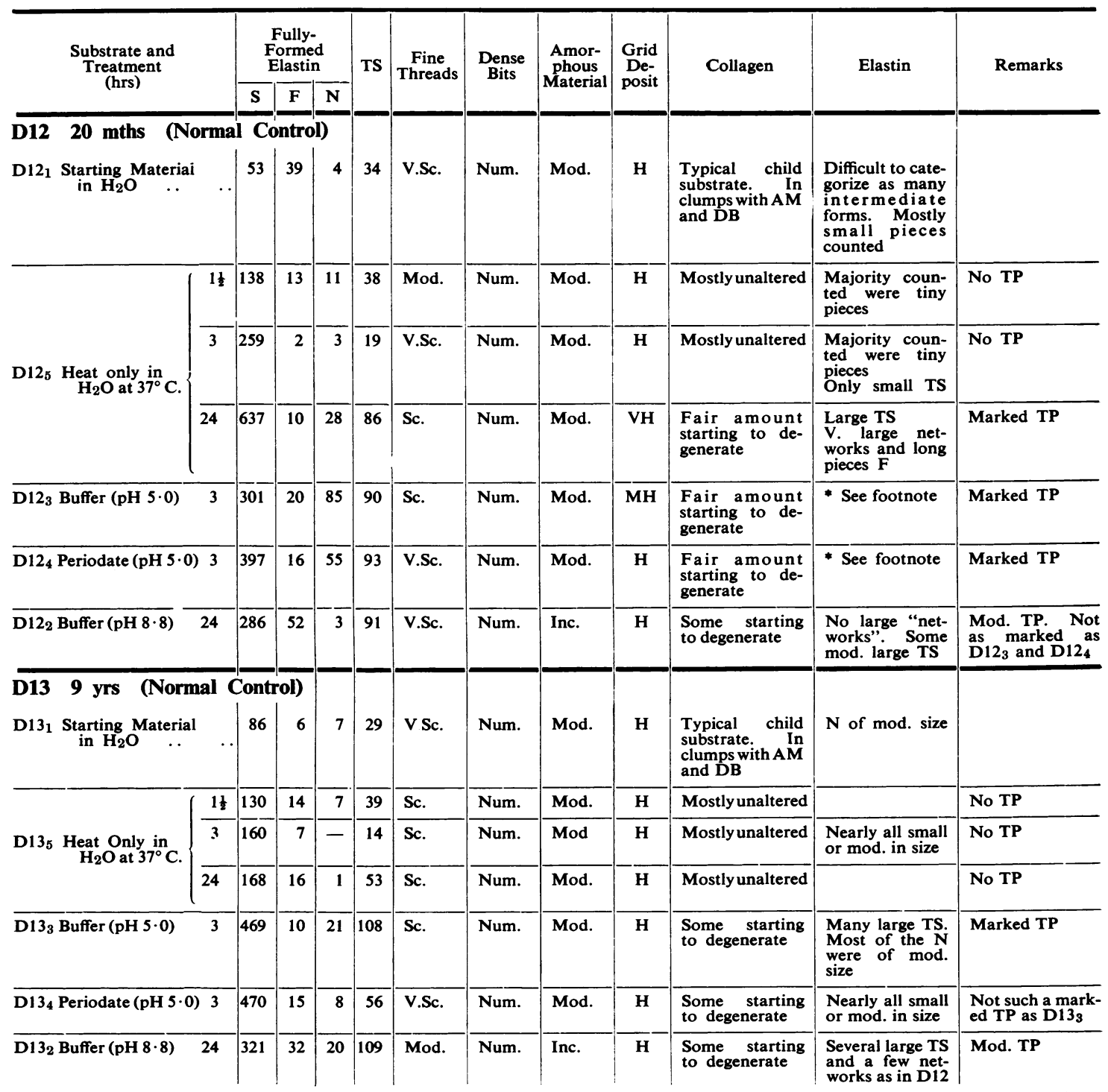


TABLE I (continued)

\begin{tabular}{|c|c|c|c|c|c|c|c|c|c|c|c|}
\hline \multirow{2}{*}{\multicolumn{3}{|c|}{ D14 19 yrs (Normal Control) }} & & \multirow[b]{3}{*}{ Num. } & \multirow{2}{*}{ 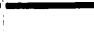 } & & & \\
\hline & & & & & & & & & & & \\
\hline $\begin{array}{c}\text { D14 }_{1} \text { Starting Material } \\
\text { in } \mathrm{H}_{2} \mathrm{O}\end{array}$ & 219 & 23 & 24 & 87 & V.Sc. & & Mod. & $\mathbf{H}$ & $\begin{array}{l}\text { In clumps mixed } \\
\text { with AM and } \\
\text { DB }\end{array}$ & $\begin{array}{l}\text { Nearly all small } \\
\text { or mod. in size }\end{array}$ & A few large TS \\
\hline $1 \underline{1}$ & 208 & 11 & 8 & 66 & Sc. & Num. & Mod. & $\mathbf{H}$ & Mostly unaltered & $\begin{array}{l}\text { Nearly all small } \\
\text { or mod. in size }\end{array}$ & $\begin{array}{l}\text { Like starting ma- } \\
\text { terial. No TP }\end{array}$ \\
\hline $\begin{array}{l}\text { D14 }{ }_{5} \text { Heat Only in } \\
\quad \mathrm{H}_{2} \mathrm{O} \text { at } 37^{\circ} \mathrm{C} .\end{array}$ & 268 & 10 & 3 & 57 & Mod. & Num. & Mod. & $\mathbf{H}$ & Mostly unaltered & $\begin{array}{l}\text { Nearly all small } \\
\text { or mod. in size }\end{array}$ & No TP \\
\hline 24 & $\overline{183}$ & 5 & 4 & 96 & V.V.Sc. & Num. & Mod. & $\mathbf{H}$ & Mostly unaltered & $\begin{array}{l}\text { Nearly all small } \\
\text { or mod. in size }\end{array}$ & No TP \\
\hline D14 3 Buffer (pH 5.0) & \multicolumn{3}{|c|}{ Not done } & & & & & & & & \\
\hline D14 4 Periodate $\left(\mathrm{pH} \mathrm{5 \cdot 0)} \quad 1 \frac{1}{2}\right.$ & \multicolumn{3}{|c|}{ Not done } & & & & & & & & \multirow[b]{2}{*}{ Marked TP } \\
\hline D14 ${ }_{3}$ Buffer (pH 5.0) & 380 & 7 & 5 & 135 & V.Sc. & Num. & Mod. & $\mathbf{H}$ & $\begin{array}{l}\text { Some starting } \\
\text { to degenerate }\end{array}$ & Inc. in large TS & \\
\hline D144 Periodate (pH 5.0) 3 & 361 & 3 & 5 & 95 & V.Sc. & Num. & Mod. & $\mathbf{H}$ & $\begin{array}{l}\text { Some starting } \\
\text { to degenerate }\end{array}$ & $\begin{array}{l}\text { Not so many } \\
\text { large TS }\end{array}$ & Mod. TP \\
\hline D14 2 Buffer (pH 8·8) & $\overline{362}$ & 14 & 3 & 123 & Mod. & Num. & Inc. & $\mathbf{H}$ & $\begin{array}{l}\text { Some starting } \\
\text { to degenerate }\end{array}$ & $\begin{array}{l}\text { Inc. in mod. } \\
\text { sized TS }\end{array}$ & Mod. TP \\
\hline \begin{tabular}{ccc} 
D5 & 43 yrs $\quad$ (Normal \\
D5 1 & $\begin{array}{c}\text { Starting } \\
\text { in } \mathrm{H}_{2} \mathrm{O}\end{array}$ \\
& \multicolumn{2}{c}{$\ldots$}
\end{tabular} & Cont & $\begin{array}{r}01) \\
1\end{array}$ & 1 & 18 & None & Few & Mod. & VH & $\begin{array}{l}\text { In clumps mixed } \\
\text { with } \mathbf{A M}\end{array}$ & $\begin{array}{l}\text { Majority coun- } \\
\text { ted were tiny } \\
\text { pieces }\end{array}$ & \\
\hline \multirow{3}{*}{$\begin{array}{l}\text { D5.) } \\
\quad \mathrm{H}_{2} \mathrm{O} \text { at } 37^{\circ} \mathrm{C} .\end{array}$} & $\overline{176}$ & 2 & - & 28 & None & Mod. & Mod. & VH & Mostly unaltered & $\begin{array}{l}\text { Majority coun- } \\
\text { ted were tiny } \\
\text { pieces }\end{array}$ & No TP \\
\hline & 350 & 2 & - & 35 & None & Mod. & Mod. & VH & Mostly unaltered & $\begin{array}{l}\text { Majority coun- } \\
\text { ted were tiny } \\
\text { pieces }\end{array}$ & No TP \\
\hline & $\overline{109}$ & - & $\overline{-}$ & $\overline{21}$ & V.Sc. & Less & Less & $\overline{\text { MH }}$ & Mostly unaltered & $\begin{array}{l}\text { Majority coun- } \\
\text { ted were tiny } \\
\text { pieces }\end{array}$ & $\begin{array}{l}\text { No TP } \\
\text { Lighter deposit }\end{array}$ \\
\hline $\mathrm{D5}_{3}$ Buffer (pH 5.0) & $\frac{1}{243}$ & 2 & 1 & 36 & None & Mod. & Mod. & $\mathbf{H}$ & Mostly unaltered & Some large TS & Mod. TP \\
\hline $\mathrm{D}_{4}$ Periodate (pH 5.0) & $\frac{1}{2} 254$ & 1 & -1 & 60 & None & Mod. & Mod. & $\mathbf{H}$ & Mostly unaltered & Some large TS & Mod. TP \\
\hline $\mathrm{DS}_{3}$ Buffer (pH 5.0) & 403 & 11 & 1 & 86 & V.Sc. & Mod. & Mod. & $\mathbf{H}$ & Mostly unaltered & Some large TS & Mod. TP \\
\hline $\mathrm{D5}_{4}$ Periodate (pH 5.0) 3 & 121 & 1 & - & 17 & None & Mod. & Mod. & $\mathbf{H}$ & $\overline{\text { Mostly unaltered }}$ & $\begin{array}{l}\text { Like starting } \\
\text { material }\end{array}$ & $\begin{array}{l}\text { Unexpected } \\
\text { picture }\end{array}$ \\
\hline $\mathrm{D} 5_{2}$ Buffer (pH 8.8) & $\overline{348}$ & 6 & 2 & 49 & V.Sc. & Mod. & Mod. & VH & Mostly unaltered & $\begin{array}{l}\text { Many tiny pieces } \\
\text { Some v. large } \\
\text { TS } \\
\end{array}$ & Mod. TP \\
\hline \begin{tabular}{c} 
D15 56 yrs (Normal \\
D15, Starting Material \\
\multicolumn{3}{c}{ in $\mathrm{H}_{2} \mathrm{O}$}
\end{tabular} & Con & $\begin{array}{c}\text { trol) } \\
16\end{array}$ & 6 & 28 & Sc. & Few & Sc. & $\mathbf{H}$ & $\begin{array}{l}\text { "Adult type" } \\
\text { unaltered colla- } \\
\text { gen often in } \\
\text { bundles }\end{array}$ & $\begin{array}{l}\text { Tiny pieces S. } \\
\text { Long th i c k } \\
\text { pieces F. small } \\
\text { Scanty, small } \\
\text { atypical TS }\end{array}$ & \\
\hline \multirow{3}{*}{$\begin{array}{l}\text { D15 } 5_{5} \text { Heat Only in } \\
\quad \mathrm{H}_{2} \mathrm{O} \text { at } 37^{\circ} \mathrm{C} .\end{array}$} & $\overline{\frac{1}{2}} \overline{181}$ & 9 & 4 & 41 & V.Sc. & Mod. & Mod. & $\mathbf{H}$ & Mostly unaltered & $\begin{array}{l}\text { Small or mod. } \\
\text { sized typical TS }\end{array}$ & $\begin{array}{l}\text { Like starting ma- } \\
\text { terial. No TP } \\
\end{array}$ \\
\hline & $\overline{202}$ & 4 & 3 & 47 & V.Sc. & Mod. & Mod. & $\mathbf{H}$ & Mostly unaltered & \begin{tabular}{|l} 
A few mod. \\
large TS
\end{tabular} & No TP \\
\hline & $\overline{244}$ & 21 & 9 & 57 & Sc. & Mod. & Mod. & $\mathbf{H}$ & Mostly unaltered & $\begin{array}{l}\text { Inc. in small and } \\
\text { mod. sized S }\end{array}$ & No TP \\
\hline Buffer (pH 5.0) & & do & & & & & & & & & \\
\hline Periodate (pH 5.0) & $\bar{N}_{c}$ & dor & & & & & & & & & \\
\hline D15 3 Buffer (pH 5.0) & $\overline{296}$ & 10 & 1 & 27 & V.Sc. & Mod. & Mod. & $\mathbf{H}$ & Mostlyunaltered & $\begin{array}{l}\text { Inc. in small and } \\
\text { mod. sized S }\end{array}$ & No TP \\
\hline D154 Periodate (pH 5.0) 3 & $\overline{318}$ & 4 & 3 & 39 & V.Sc. & Mod. & Mod. & $\mathbf{H}$ & Mostly unaltered & $\begin{array}{l}\text { Mod. large typi- } \\
\text { cal TS }\end{array}$ & No TP \\
\hline D15 2 Buffer (pH 8.8) & 280 & 17 & 3 & 34 & Sc. & Inc. & Inc. & $\mathbf{H}$ & Mostly unaltered & $\begin{array}{l}\text { Inc. in small and } \\
\text { mod. sized S }\end{array}$ & No TP \\
\hline
\end{tabular}


TABLE I (continued)

\section{GROUP II. SUBSTRATES EXHIBITING COLLAGENASE RESISTANCE}

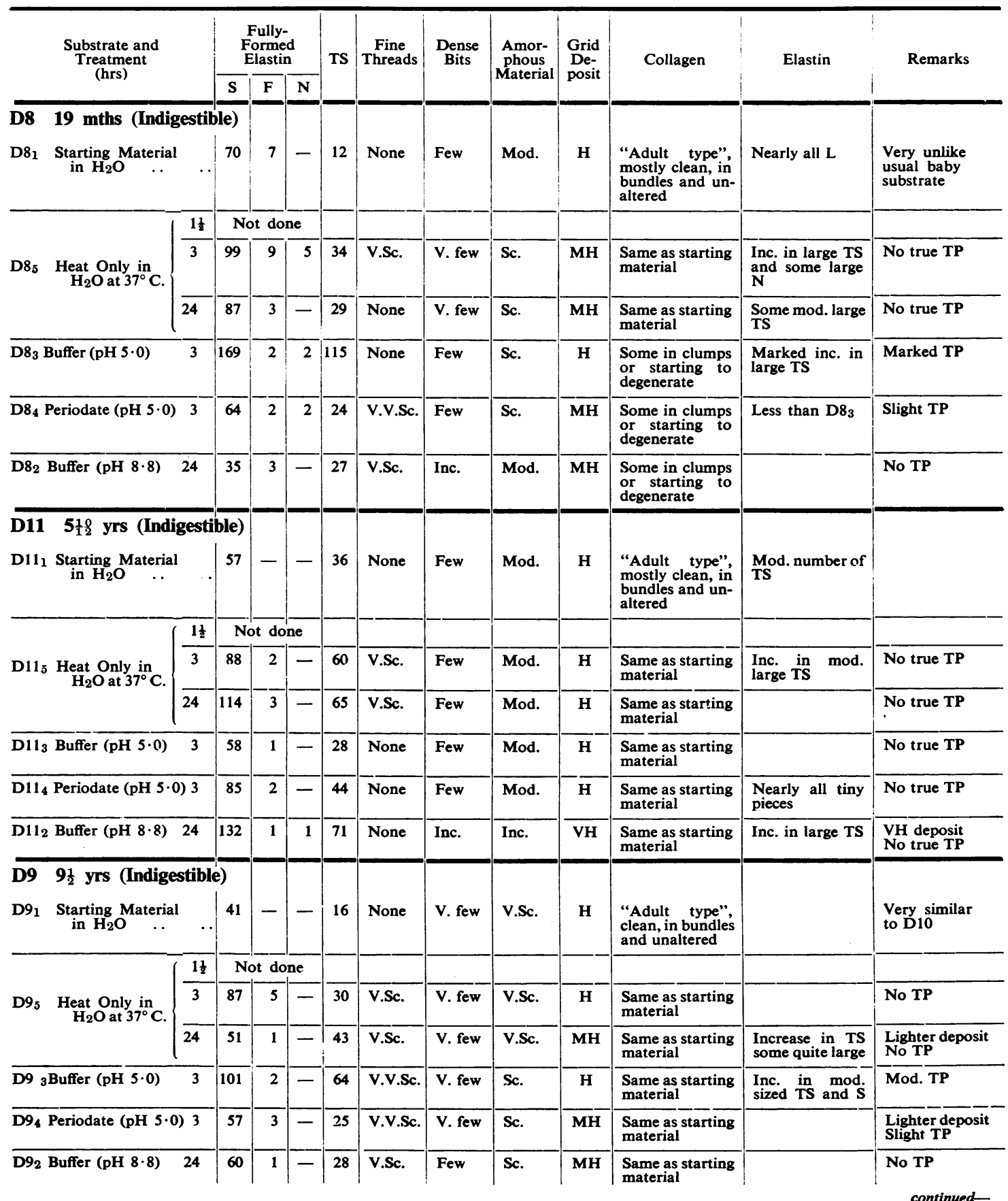


TABLE I (continued)

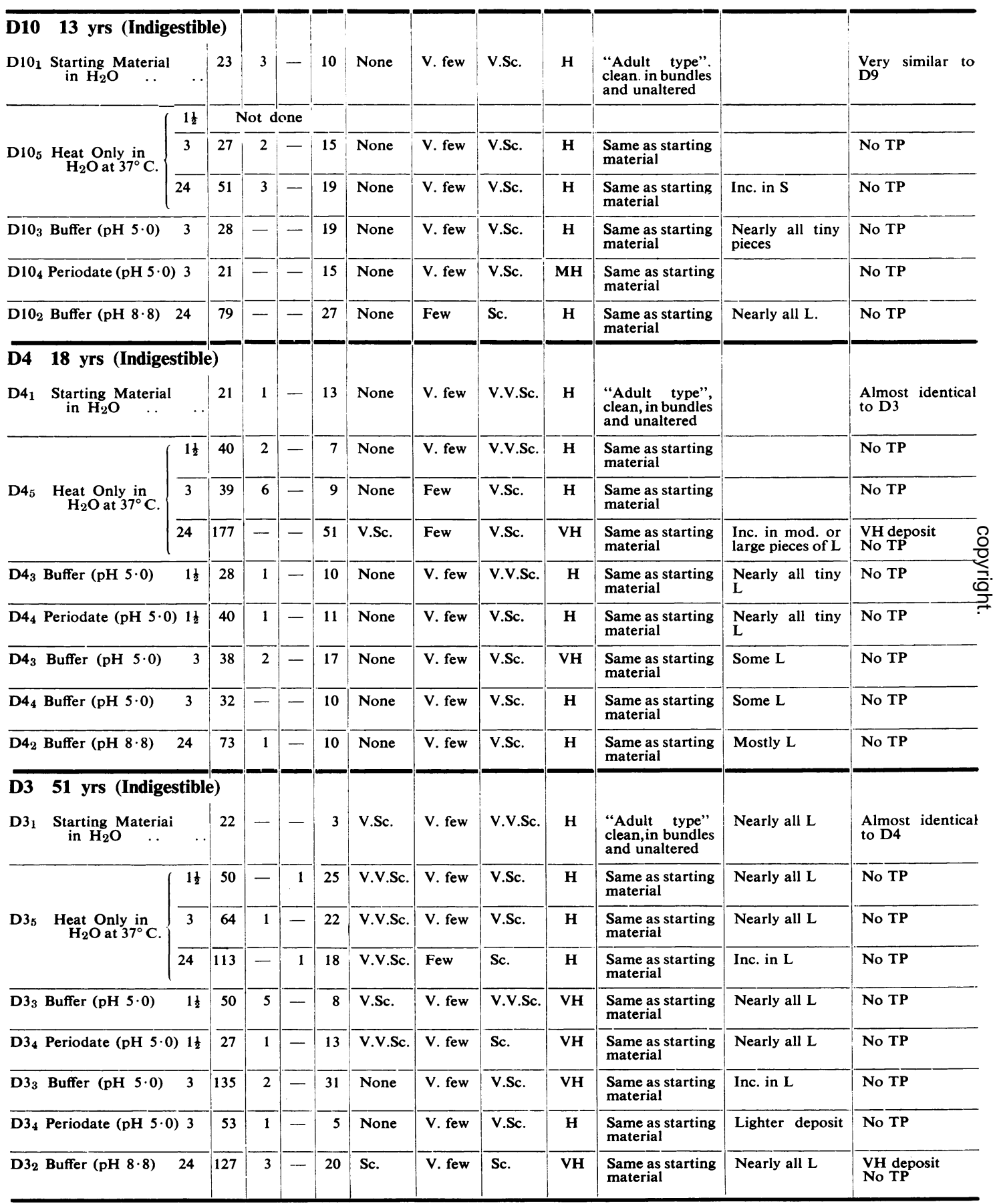


TABLE I (continued)

GROUP III. SUBSTRATES EXHIBITING EXCESSIVE COLLAGENASE DIGESTION

\begin{tabular}{|c|c|c|c|c|c|c|c|c|c|c|c|c|c|}
\hline \multirow{2}{*}{\multicolumn{3}{|c|}{$\begin{array}{c}\text { Substrate and } \\
\text { Treatment } \\
\text { (hrs) }\end{array}$}} & \multicolumn{3}{|c|}{$\begin{array}{l}\text { Fully- } \\
\text { Formed } \\
\text { Elastin }\end{array}$} & \multirow[t]{2}{*}{ TS } & \multirow[t]{2}{*}{$\begin{array}{c}\text { Fine } \\
\text { Threads }\end{array}$} & \multirow[t]{2}{*}{$\begin{array}{l}\text { Dense } \\
\text { Bits }\end{array}$} & \multirow{2}{*}{$\begin{array}{c}\text { Amor- } \\
\text { phous } \\
\text { Material }\end{array}$} & \multirow{2}{*}{$\begin{array}{l}\text { Grid } \\
\text { De- } \\
\text { posit }\end{array}$} & \multirow[t]{2}{*}{ Collagen } & \multirow[t]{2}{*}{ Elastin } & \multirow[t]{2}{*}{ Remarks } \\
\hline & & & $\mathbf{S}$ & $\mathbf{F}$ & $\overline{\mathbf{N}}$ & & & & & & & & \\
\hline \multicolumn{14}{|c|}{ D6 20 yrs (Overdigestible) } \\
\hline D6 1 & $\begin{array}{l}\text { Starting Material } \\
\text { in } \mathrm{H}_{2} \mathrm{O}\end{array}$ & & 65 & 1 & - & 3 & Sc. & Few & Mod. & $\mathbf{H}$ & $\begin{array}{l}\text { In clumps mixed } \\
\text { with AM and } \\
\text { DB. Some de- } \\
\text { generation }\end{array}$ & $\begin{array}{l}\text { Nearly all tiny } \\
\text { pieces } \\
\text { Only three TS }\end{array}$ & $\begin{array}{l}\text { Resembled a con- } \\
\text { trol child sub- } \\
\text { strate }\end{array}$ \\
\hline \multirow{3}{*}{ D65 } & \multirow{3}{*}{$\begin{array}{c}\text { Heat Only in } \\
\mathrm{H}_{2} \mathrm{O} \text { at } 37^{\circ} \mathrm{C} \text {. }\end{array}$} & $1 \frac{1}{2}$ & 157 & 4 & 5 & 34 & Sc. & Few & Mod. & MH & $\begin{array}{l}\text { Same as starting } \\
\text { material }\end{array}$ & $\begin{array}{l}\text { Inc. in mod. } \\
\text { large TS }\end{array}$ & No true TP \\
\hline & & 3 & 138 & 3 & 6 & 29 & Sc. & Few & Mod. & $\mathbf{H}$ & $\begin{array}{l}\text { Same as starting } \\
\text { material }\end{array}$ & A few large TS & No true TP \\
\hline & & 24 & 136 & 4 & 4 & 32 & Mod. & Few & Mod. & MH & $\begin{array}{l}\text { More collagen } \\
\text { starting to de- } \\
\text { generate }\end{array}$ & A few large TS & No true TP \\
\hline $\mathrm{Db}_{3}$ & Buffer (pH 5.0) & $1 \frac{1}{2}$ & \multicolumn{3}{|c|}{ Not done } & & & & & & & & \\
\hline \multicolumn{3}{|c|}{ D64 Periodate (pH 5.0) $1 \frac{1}{2}$} & \multicolumn{3}{|c|}{ Not done } & & & & & & & & \\
\hline $\mathrm{D6}_{3}$ & Buffer (pH 5.0) & 3 & 298 & 1 & - & 56 & Sc. & $\begin{array}{l}\text { Mark- } \\
\text { ed inc. }\end{array}$ & $\begin{array}{l}\text { Marked } \\
\text { inc. }\end{array}$ & VH & $\begin{array}{l}\text { More collagen } \\
\text { starting to de- } \\
\text { generate }\end{array}$ & Inc. in large $\mathrm{TS}$ & Very marked TP \\
\hline $\mathrm{D6}_{4}$ & Periodate $(\mathrm{pH} 5 \cdot 0$ & 3 & 456 & 3 & 1 & 33 & Sc. & $\begin{array}{l}\text { Slight } \\
\text { inc. }\end{array}$ & $\begin{array}{l}\text { Slight } \\
\text { inc. }\end{array}$ & $\mathbf{H}$ & $\begin{array}{l}\text { Some starting to } \\
\text { degenerate }\end{array}$ & Some large TS & Mod. TP \\
\hline$\overline{\text { D62 }}$ & Buffer (pH 8.8) & 24 & 171 & 7 & - & 38 & Many & $\begin{array}{l}\text { Slight } \\
\text { inc. }\end{array}$ & $\begin{array}{l}\text { Slight } \\
\text { inc. }\end{array}$ & MH & $\begin{array}{l}\begin{array}{l}\text { Some starting to } \\
\text { degenerate }\end{array} \\
\end{array}$ & Some large TS & $\begin{array}{l}\text { Lighter deposit } \\
\text { Mod. TP }\end{array}$ \\
\hline \multicolumn{6}{|c|}{ D7 52 yrs (Overdigestible) } & & & & & & & & \\
\hline \multirow[t]{2}{*}{ D7 1} & $\begin{array}{c}\text { Starting Material } \\
\text { in } \mathrm{H}_{2} \mathrm{O}\end{array}$ & & 102 & - & 2 & 12 & Sc. & Few & Mod. & $\mathbf{H}$ & $\begin{array}{l}\text { Both separate } \\
\text { and in clumps } \\
\text { with AM. A } \\
\text { little degen. }\end{array}$ & $\begin{array}{l}\text { Nearly all tiny } \\
\text { pieces }\end{array}$ & $\begin{array}{l}\text { Resembled a } \\
\text { young adult con- } \\
\text { trol substrate }\end{array}$ \\
\hline & & $1 \frac{1}{2}$ & 119 & 1 & 1 & 24 & None & Few & Mod. & VH & $\begin{array}{l}\text { Same as starting } \\
\text { material }\end{array}$ & $\begin{array}{l}\text { Nearly all tiny } \\
\text { pieces }\end{array}$ & No TP \\
\hline \multirow[t]{2}{*}{ D7 5} & $\begin{array}{l}\text { Heat Only in } \\
\mathrm{H}_{2} \mathrm{O} \text { at } 37^{\circ} \mathrm{C} .\end{array}$ & 3 & $\overline{268}$ & 7 & 2 & 36 & None & Inc. & Inc. & VH & $\begin{array}{l}\begin{array}{l}\text { More degen. } \\
\text { coll. }\end{array} \\
\end{array}$ & Several large TS & No true TP \\
\hline & & 24 & 82 & 1 & 2 & 18 & Sc. & Few & Mod. & MH & $\begin{array}{l}\begin{array}{l}\text { More degen. } \\
\text { coll. }\end{array} \\
\end{array}$ & Lighter deposit & No true TP \\
\hline $\mathrm{D7}_{3}$ & Buffer (pH 5.0) & $1 \frac{1}{2}$ & 445 & 5 & 1 & 51 & None & $\begin{array}{l}\text { Mark- } \\
\text { ed inc. }\end{array}$ & $\begin{array}{l}\text { Mark- } \\
\text { ed inc. }\end{array}$ & $\mathbf{H}$ & $\begin{array}{l}\text { Some degen. } \\
\text { coll. }\end{array}$ & $\begin{array}{l}\text { Inc. in TS and } \\
\mathbf{S}\end{array}$ & Marked TP \\
\hline$\overline{D 74}$ & Periodate (pH 5.0 & $1 \frac{1}{2}$ & 311 & 5 & 2 & 39 & Sc. & $\begin{array}{l}\text { Mod. } \\
\text { inc. }\end{array}$ & $\begin{array}{l}\text { Mod. } \\
\text { inc. }\end{array}$ & $\mathbf{H}$ & $\begin{array}{l}\begin{array}{l}\text { Some degen. } \\
\text { coll. }\end{array} \\
\end{array}$ & $\begin{array}{l}\text { Inc. in TS and } \\
\mathbf{S}\end{array}$ & Mod. TP \\
\hline D7 3 & Buffer (pH 5.0) & 3 & 265 & 8 & 1 & 51 & V.V.Sc. & $\begin{array}{l}\text { Mod. } \\
\text { inc. }\end{array}$ & $\begin{array}{l}\text { Mod. } \\
\text { inc. }\end{array}$ & $\mathbf{H}$ & $\begin{array}{l}\text { Some degen. } \\
\text { coll. }\end{array}$ & Some large TS & Mod. TP \\
\hline D7 4 & Periodate $(\mathrm{pH} 5.0$ & 3 & 235 & 2 & 1 & 30 & V.V.Sc. & $\begin{array}{l}\text { Mod. } \\
\text { inc }\end{array}$ & $\begin{array}{l}\text { Mod. } \\
\text { inc. }\end{array}$ & $\mathbf{H}$ & $\begin{array}{l}\begin{array}{l}\text { Some degen. } \\
\text { coll. }\end{array} \\
\end{array}$ & & Mod. TP \\
\hline D7 2 & Buffer (pH 8.8) & 24 & 252 & 9 & 2 & 47 & Sc. & $\begin{array}{l}\text { Mod. } \\
\text { inc. }\end{array}$ & $\begin{array}{l}\text { Mod. } \\
\text { inc. }\end{array}$ & $\mathbf{H}$ & $\begin{array}{l}\begin{array}{l}\text { Some degen. } \\
\text { coll. }\end{array} \\
\end{array}$ & $\begin{array}{l}\text { Nearly all tiny } \\
\text { pieces of } S\end{array}$ & Mod. TP \\
\hline
\end{tabular}

* The $\mathbf{N}$ recorded were very large "networks" representing the completed conversion of the transformation structures (TS) into "Elastin". The division between some of the TS and these large "networks" was arbitrary.

$\mathbf{L}=$ tiny pieces of elastin presenting a stippled or lumpy appearance (as in Fig. 13).

$\mathbf{S}=$ skin-type elastin; $\mathbf{F}=$ filamenting elastin; $\mathbf{N}=$ natural elastin network; Num. = numerous ; Mod. = moderate; TS $=$ transformation structure; $\mathbf{T P}=$ transformation picture; $\mathbf{D B}=$ dense bits; $\mathbf{A M}=$ amorphous material; $\mathbf{H}=$ heavy; $\mathbf{Y}^{\prime} \mathbf{H}=$ very heavy; $\mathbf{M H}=$ moderately heavy; V.Sc. = very scanty; degen. = degenerating; Inc. = increased.

$$
\text { Total "elastin" counts }\left\{\begin{array}{l}
\text { from the two substrates in Group III }=4.124 \\
\text { from the six substrates in Group II } \\
\text { from the five substrates in Group I }
\end{array}\right.
$$


ANALYSIS OF INCREASE IN "EL

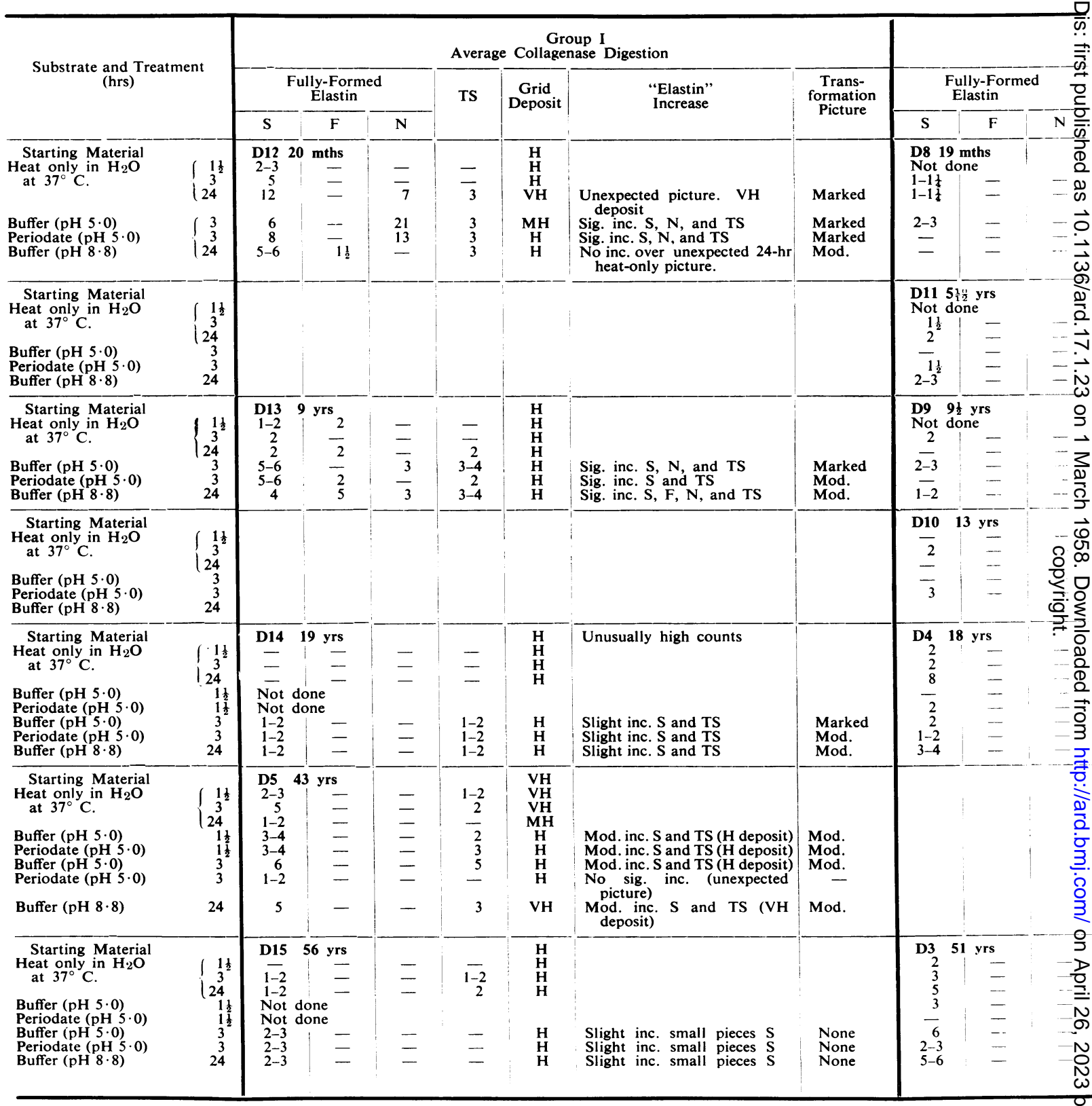

Figures represent number of times "elastin" content increased over that present in starting material.

$$
\begin{aligned}
& \mathbf{S}=\text { Skin-type elastin. } \\
& \mathbf{F}=\text { Filamenting elastin. } \\
& \mathbf{N}=\text { Natural elastin network. } \\
& \text { TS }=\text { Transformation structure. } \\
& \text { Mod. } \\
& \text { = Moderate. }
\end{aligned}
$$


TABLE III

SUMMARIZED ELECTRON MICROSCOPIC CHARACTERISTICS OF THE THREE GROUPS

\begin{tabular}{|c|c|c|c|}
\hline Group & $\begin{array}{l}\text { I } \\
\text { Average Collagenase } \\
\text { Digestion }\end{array}$ & $\begin{array}{l}\text { II } \\
\text { Collagenase- } \\
\text { Resistant }\end{array}$ & 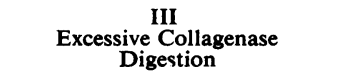 \\
\hline$\overline{\text { Starting Material }}$ & $\begin{array}{l}\text { Usual age differences } \\
\text { In young subjects collagen } \\
\text { often in clumps with abun- } \\
\text { dant amorphous material } \\
\text { and dense bits } \\
\text { In older subjects cleaner col- } \\
\text { lagen in bundles with less } \\
\text { amorphous material and } \\
\text { dense bits } \\
\text { Elastin tended to increase with } \\
\text { age }\end{array}$ & $\begin{array}{l}\text { Very little age difference } \\
\text { All very similar, consisting } \\
\text { of bundles of clean collagen } \\
\text { and hardly any amorphous } \\
\text { material and dense bits } \\
\text { Elastin tended to decrease } \\
\text { with age }\end{array}$ & $\begin{array}{l}\text { Resembled Group I specimens } \\
\text { from younger age groups; } \\
\text { e.g. 20-yr-old was similar to } \\
\text { substrate from a child control }\end{array}$ \\
\hline Elastin & & $\begin{array}{l}\text { Much scantier than Groups } \\
\text { I and III after all treat- } \\
\text { ments } \\
\text { High proportion of } L^{*} \\
\text { Many small bundles of col- } \\
\text { lagen resembling elastin } \\
\text { (Fig. 9) }\end{array}$ & \\
\hline $\begin{array}{l}\text { Response to Heating in } \mathrm{H}_{2} \mathrm{O} \text { up } \\
\text { to } 24 \mathrm{hrs} \text { at } 37^{\circ} \mathrm{C} \text {. }\end{array}$ & $\begin{array}{l}\text { Slight increase in skin-type } \\
\text { "elastin" } \\
\text { No transformation picture }\end{array}$ & $\begin{array}{l}\text { Slight increase in skin-type } \\
\text { "elastin" and transforma- } \\
\text { tion structures } \\
\text { No transformation picture }\end{array}$ & $\begin{array}{l}\text { Slight increase in skin-type } \\
\text { "elastin" and transformation } \\
\text { structures } \\
\text { No transformation picture }\end{array}$ \\
\hline $\begin{array}{l}\text { Response to Borate Buffer (pH } \\
8 \cdot 8) 24 \text { hrs at } 37^{\circ} \mathrm{C} \text {. }\end{array}$ & $\begin{array}{l}\text { Moderate transformation pic- } \\
\text { ture in children and young } \\
\text { adults } \\
\text { Increase in amorphous mater- } \\
\text { ial and dense bits }\end{array}$ & $\begin{array}{l}\text { No effect except slight in- } \\
\text { crease in amorphous mater- } \\
\text { ial and dense bits }\end{array}$ & $\begin{array}{l}\text { Moderate transformation pic- } \\
\text { ture equal to younger control } \\
\text { subjects }\end{array}$ \\
\hline $\begin{array}{l}\text { Response to Phthalate Buffer } \\
(\mathrm{pH} 5 \cdot 0) \\
3 \mathrm{hrs} \text { at } 37^{\circ} \mathrm{C} \text {. }\end{array}$ & $\begin{array}{l}\text { Marked transformation pic- } \\
\text { ture under } 20 \text { yrs, moderate } \\
\text { in } 43 \text {-yr-old, and absent in } \\
56-y r-o l d\end{array}$ & $\begin{array}{l}\text { Marked transformation pic- } \\
\text { ture in infant and moderate } \\
\text { in } 9 \frac{1}{2}-y r-o l d \\
\text { Otherwise no effect }\end{array}$ & $\begin{array}{l}\text { Transformation picture } \\
\text { marked in } 20 \text {-yr-old and } \\
\text { marked in } 52 \text {-yr-old }\end{array}$ \\
\hline $\begin{array}{l}\text { Response to Periodate in Phtha- } \\
\text { late Buffer (pH } 5 \cdot 0 \text { ) } 3 \text { hrs at } \\
37^{\circ} \text { C. }\end{array}$ & $\begin{array}{l}\text { Less effect in same substrates } \\
\text { as responded to phthalate } \\
\text { buffer alone }\end{array}$ & No effect & $\begin{array}{l}\text { Less effect than to phthalate } \\
\text { buffer alone, giving moderate } \\
\text { transformation picture }\end{array}$ \\
\hline
\end{tabular}

* $\mathbf{L}=$ tiny pieces of elastin presenting a stippled or lumpy appearance as illustrated in Fig. 13.

were seen throughout all the experiments performed on this particular substrate.

A totally different picture was found in the group that did not digest after incubation with collagenase (Group II). The starting materials were very similar to each other (Figs 2, 3, 4, and 7). Even the substrate from the infant (D8, Fig. 2) closely resembled that found in the adults, with bundles of clean, unaltered collagen fibrils. There was also a notable absence of amorphous material and dense bits, which caused small bundles of collagen to resemble filamenting elastin on the electron microscopic viewing screen. Continual examination through the magnifying eyepiece was necessary to get a correct "elastin" count throughout this group (Fig. 9).

The two substrates exhibiting excessive collagenase digestion (Group III) resembled younger specimens of the control group: the 20-year-old (D6, dead of fulminating acute rheumatic carditis) could be mistaken for a child's dermis, and the 52-year-old (D7, who had received intravenous nitrogen mustard 4 days before death as therapy for carcinoma of the lung) resembled the dermis of a young adult.

In all three groups, the majority of the "elastin" counted was in tiny pieces, and frequently presented a stippled or lumpy appearance in Group II (Fig. 13a-c). As already mentioned, occasional large, dense, square-ended fibres, similar to those found in untreated, fresh whole dermis (Keech and Reed, 1957) were seen in all the prepared substrates used in the present study (Figs 10-12). The transformation structures (TS), described above and present in all the prepared starting materials, appear to be an altered form of these naturally-occurring dermal components.

In Groups I and III the elastin content of the starting material showed a tendency to increase with age: an exception was the unexpectedly high count in the 19-year-old substrate (D14). In Group II not only was the elastin scanty but the trend appeared to be in the reverse direction.

Treatment in $\mathrm{H}_{2} \mathrm{O}$ at $37^{\circ} \mathrm{C}$.- - Table I shows that heat alone produced a progressive increase in 
The scale marked on all the figures represents $1 \mu$ and all the preparations were shadowed with chromium

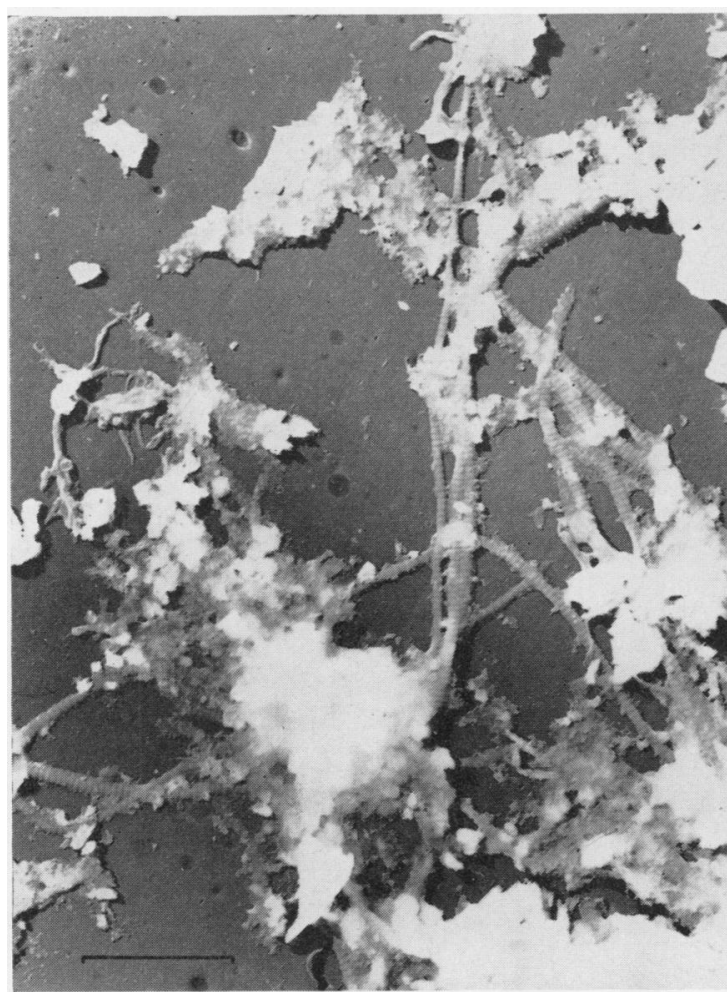

Fig. 1.-Prepared abdominal skin collagen from an infant aged 20 months (Control group D12). This starting material shows the striated collagen fibrils mixed with, and partially obscured by, the plentiful amorphous material and dense bits.

skin-type "elastin" counts in all groups, directly proportional to the length of incubation. This effect, therefore, must be taken into account when assessing the action of any chemical treatment. Group II reacted least, whereas Group III and the youngest member of Group I gave the greatest reactions. In fact, the $24-\mathrm{hr}$ picture in $\mathrm{D} 12_{5}$ was unexpected and gave a much higher count than any other treatment, aided by a very heavy grid deposit. Another substrate (the 20-year-old D6 from Group III that resembled a control child dermis) reacted in a similar fashion, together with a marked increase in TS, in spite of only moderately heavy grid deposits. Apart from those just mentioned, the majority of the substrates showed an increase in skin-type "elastin" two or three times greater than that present in the starting material (Table II), this increase consisting almost entirely of tiny or moderately-sized pieces and not constituting a transformation picture as defined above.

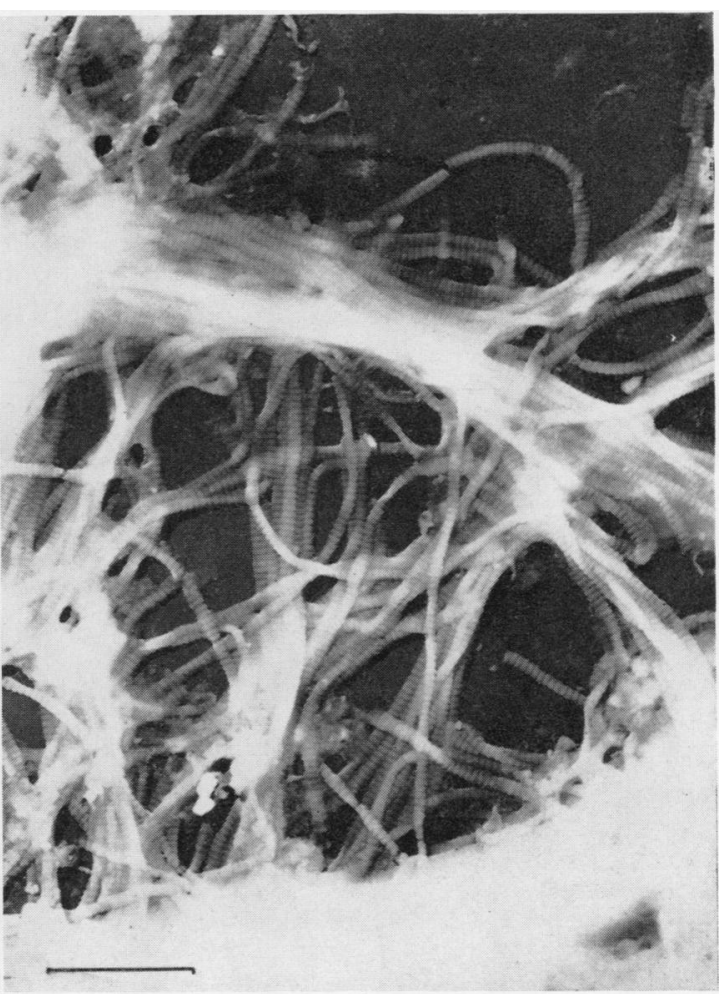

Fig. 2.-Starting material from an infant aged 19 months (Collagenaseresistant group D8). In contrast to Fig. 1 the substrate consists of bundles of clean collagen fibrils with a notable absence of amorphous material and dense bits.

$\mathrm{N}$ (Fig. 14), mentioned in the elastin columns of Table I, denotes the medium-sized, compact structures previously described (Keech, Reed, and Wood, 1956). However, heat alone on the substrates from both the infants (D12 and D8) produced large networks, sometimes stretching over several microscopic fields (20-30 $\mu$ in length), and composed of loosely-knit, winding bundles of filamenting "elastin" (Fig. 15). This was much more marked in D12 than D8.

Effect of Phthalate Buffer (pH 5.0) Alone at $37^{\circ} \mathrm{C}$. (Tables I and II).-3-hr incubation samples were examined throughout all groups, but only four substrates were examined at $1 \frac{1}{2} \mathrm{hrs}$, as it was found that a better response occurred with longer incubation. A significant increase (above that which could be accounted for by heat alone) was found in both skin-type and TS throughout Groups I and III, and in two of the younger subjects gave the 


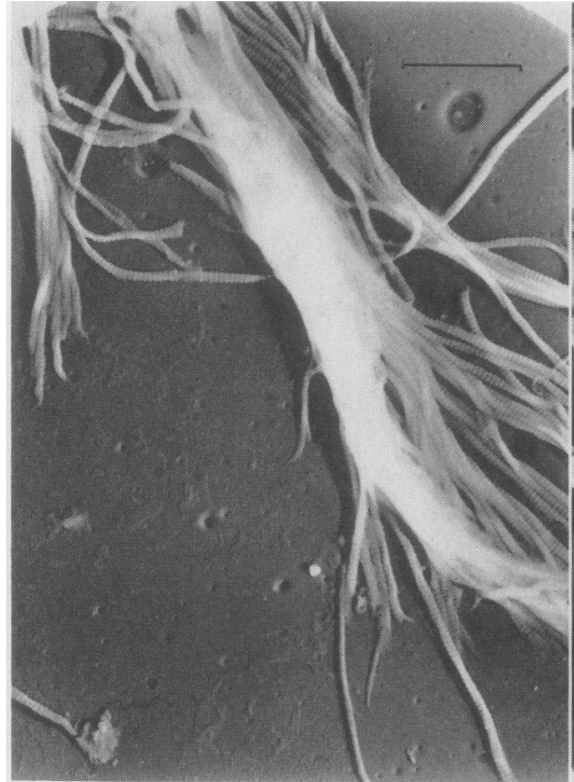

Fig. 3.-Starting material from an individual aged 18 years (Collagenase-resistant group D4). Again the substrate is typical of Group II. Compare with Figs 2, 4, and 7.

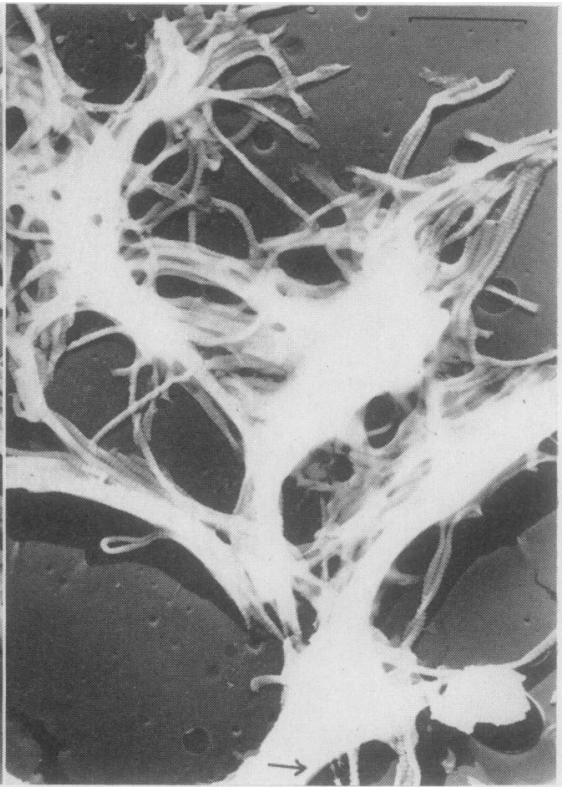

Fig. 4. - Starting material from a 13-year-old substrate (Collagenase-resistant group D10). This is again typical of Group II. The arrow indicates part of a collagen fibril under tension, as illustrated and described previously (Keech and others, 1956).

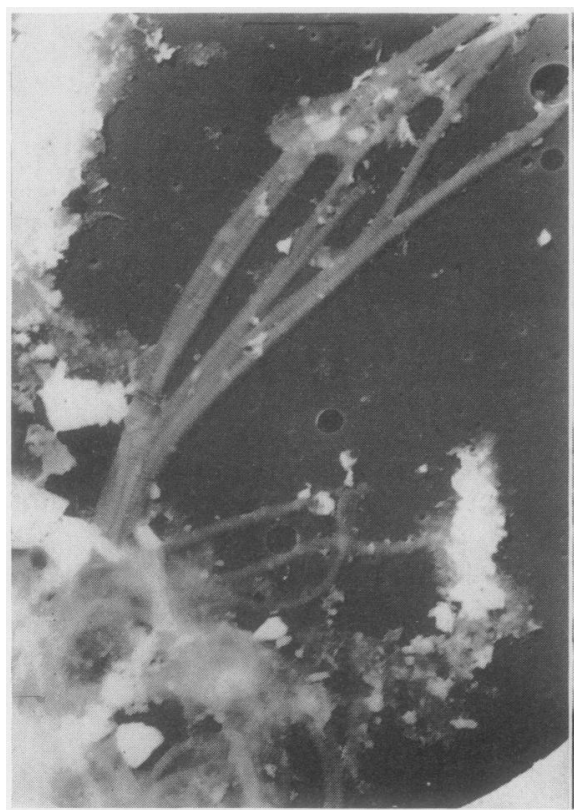

Fig. 5.- Starting material from an individual aged 19 years (Control group D14). The collagen is mixed with a moderate amount of amorphous material and dense bits.

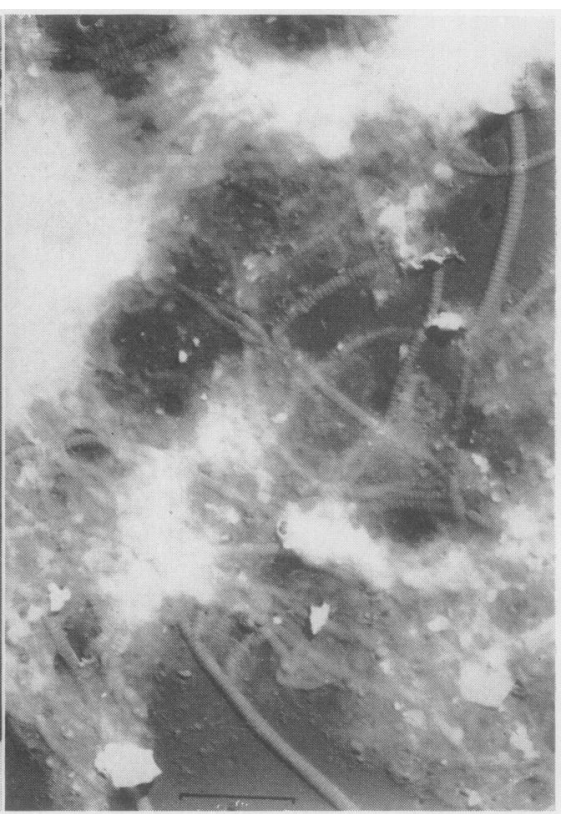

Fig. 6.- Starting material from a 20-year-old substrate (Group exhibiting excessive collagenase digestion D6). Compared with the control of the same age (Fig. 5), a fair number of the collagen fibrils are starting to degenerate, and the general picture on the electron microscopic viewing screen resembled younger specimens from the control group. 


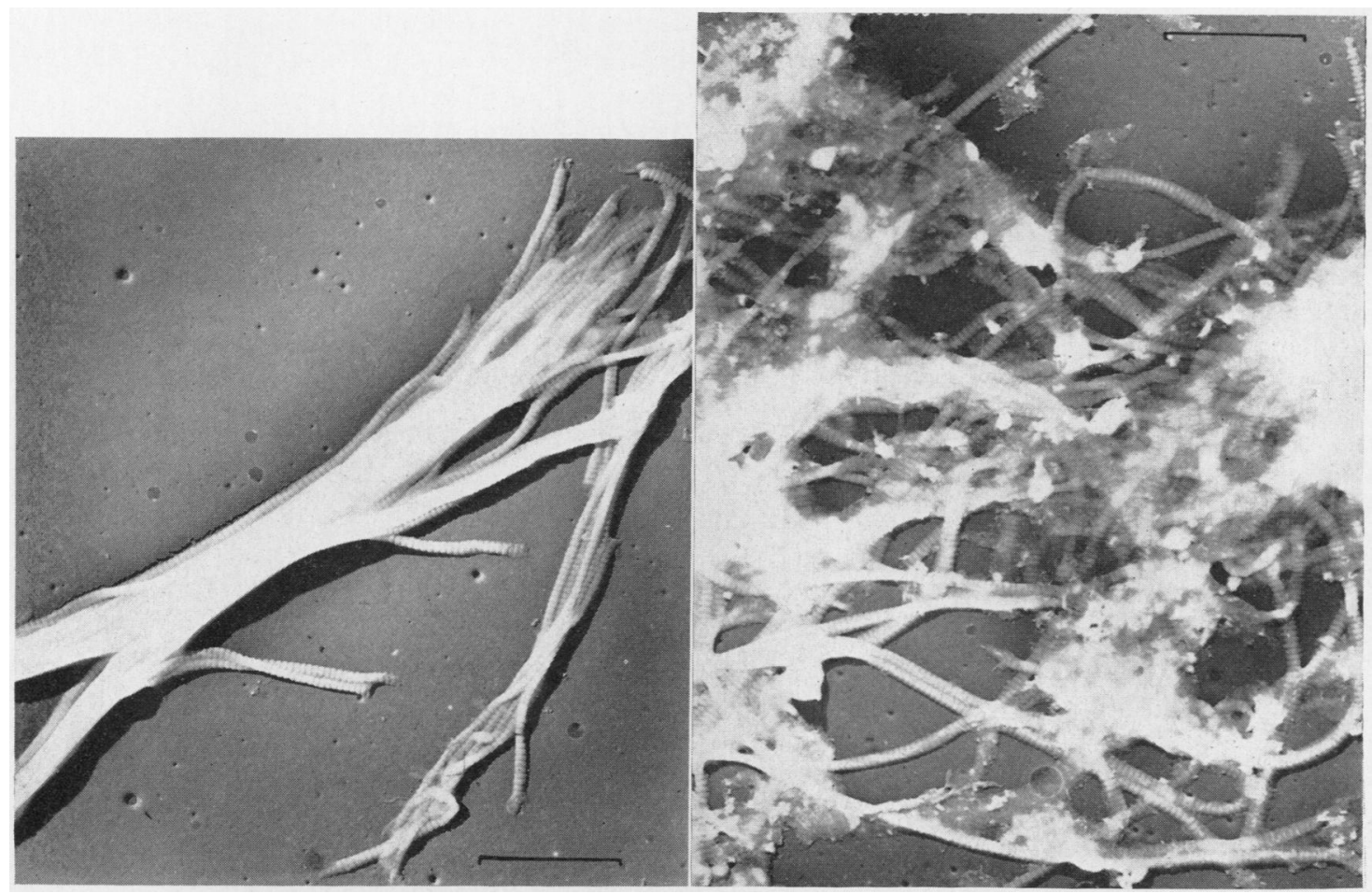

Fig. 7.-Starting material from an individual aged 51 years (Collagenase-resistant group D3), showing the substrate typical of this group. Compare with Fig. 8.

Fig. 8.-Starting material from a 56-year-old adult (Control group) The collagen is mixed with a small amount of amorphous material and a few dense bits. Compare with Fig. 7.

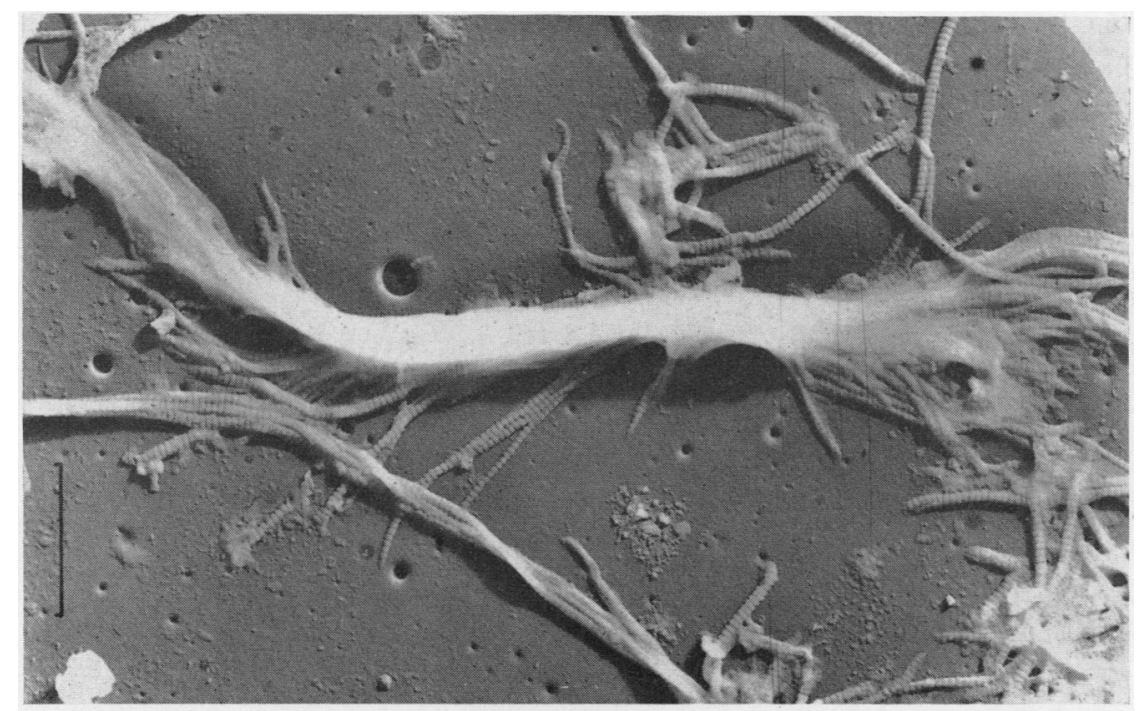

Fig. 9.-Two examples of bundles of collagen, partially coated with a thin layer of amorphous material which resembled filamenting elastin on the electron microscopic viewing screen. These were characteristic. of Group II. 


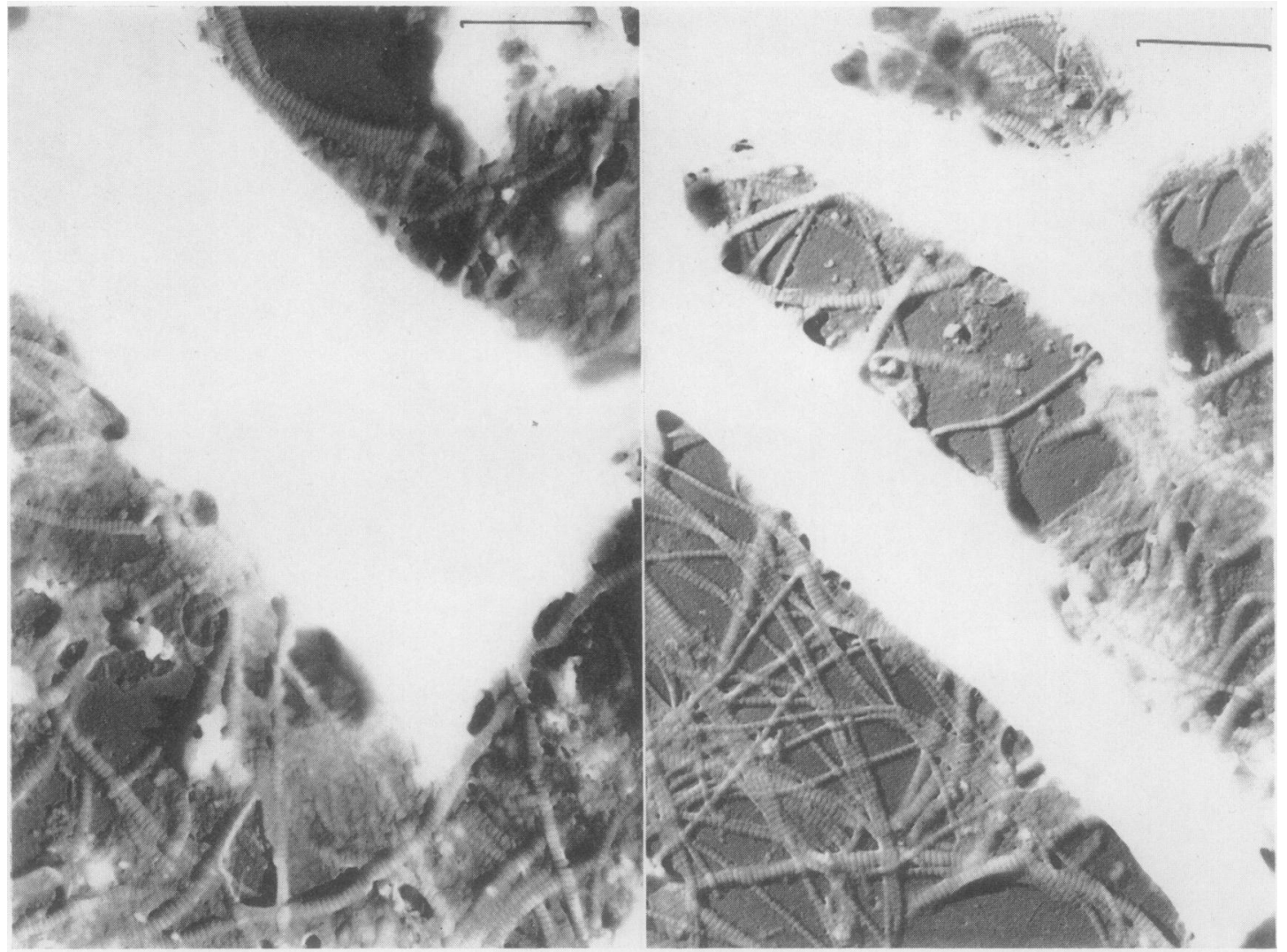

Figs 10 and 11.-Examples of square-ended, large, dense fibres from the fresh whole dermis of a 66-year-old adult. These were seen in both fresh and prepared dermis from all age groups, and sometimes splayed out into a bundle of collagen fibrils.

Fig. 12.-Starting material from a $9 \frac{1}{2}$-year-old child (Collagenase-resistant group D9), showing a branched example of the large dense fibres illustrated in Figs 10 and 11.

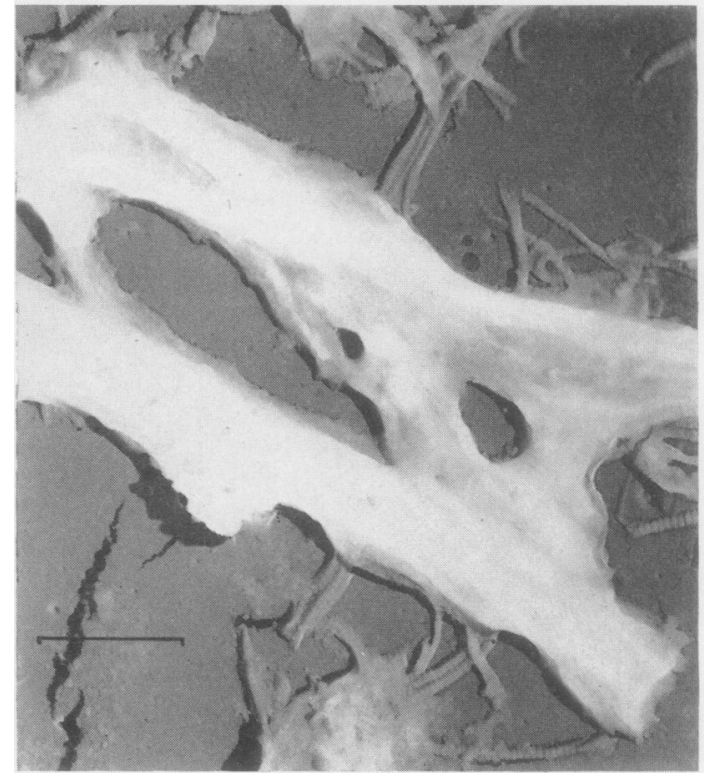




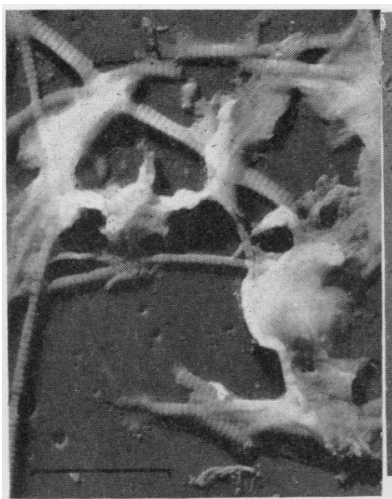

(a)

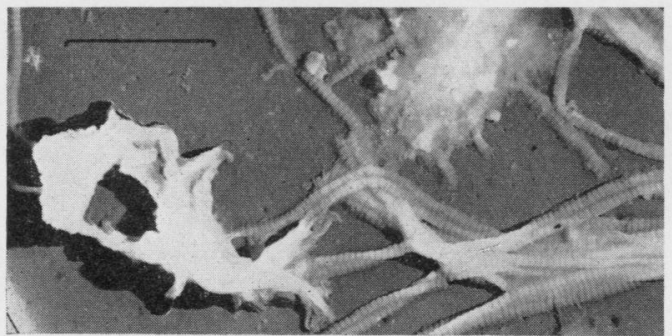

(c)

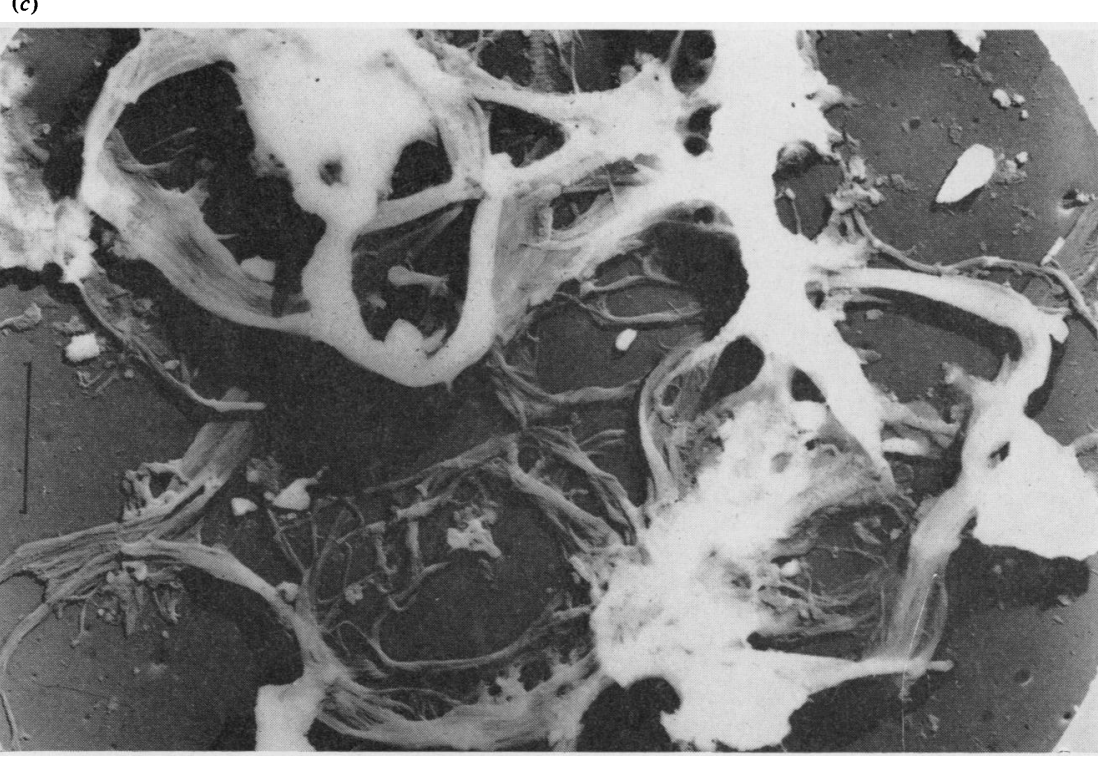

Fig. 15.-In contrast to Fig. 14, when the substrates from both the infants (D12 and D8) were heated in water at $37^{\circ} \mathrm{C}$., large networks were produced, sometimes stretching over several microscopic fields. These networks measured $20-30 \mu$ in length, and were composed of loosely-knit, winding bundles of filamenting "elastin".

highest readings, e.g. D12 and D13, in which the network counts were also significantly raised. In contrast, the 56-year-old control exhibited a slight increase in small pieces of skin-type only, and the majority of Group II were unresponsive. In the substrates which responded, a marked transformation picture was produced in the younger subjects (Fig. 37) and in Group III, but only a moderate 
transformation occurred in the 43-year-old adult control and the $9 \frac{1}{2}$-year-old indigestible.

Effect of Periodate in Phthalate Buffer (pH 5.0) at $37^{\circ} C$. (Tables I and II).--Samples were examined after the same periods of incubation as were used in the experiment with buffer alone. A definite, but less marked, response was found in all the substrates in Groups I and III that reacted to buffer alone to give a moderate transformation picture (Figs 16 and 17), but no effect was produced in the group resistant to collagenase.

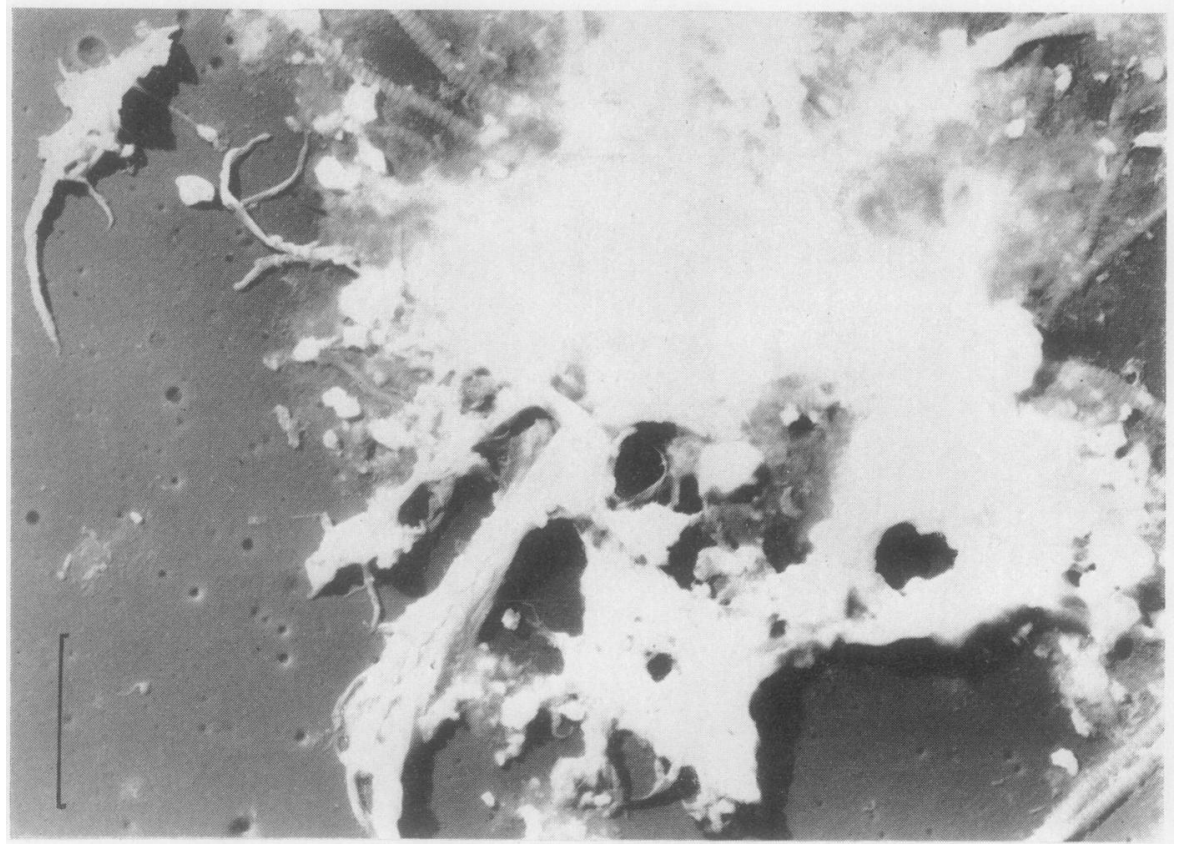

Fig. 16.-Effect of phthalate buffer (pH $5 \cdot 0)$ alone on the 19year-old substrate (D14) from the Control group. After 3 hrs' incubation at $37^{\circ} \mathrm{C}$., a transformation picture was found, with a significant increase in the "elastin" counts. This shows degenerating collagen mixed with amorphous material and elastin-like structures Compare with Fig. 17.

Fig. 17.-Effect of periodate in phthalate buffer (pH 5.0) on the 20-year-old substrate exhibiting excessive collagenase digestion (D6). A transformation picture was found after 3 hrs' incubation at $37^{\circ} \mathrm{C}$. with collagen (some of which was starting to degenerate) mixed with amorphous material and elastin-like structures.

Compare with Fig. 16.

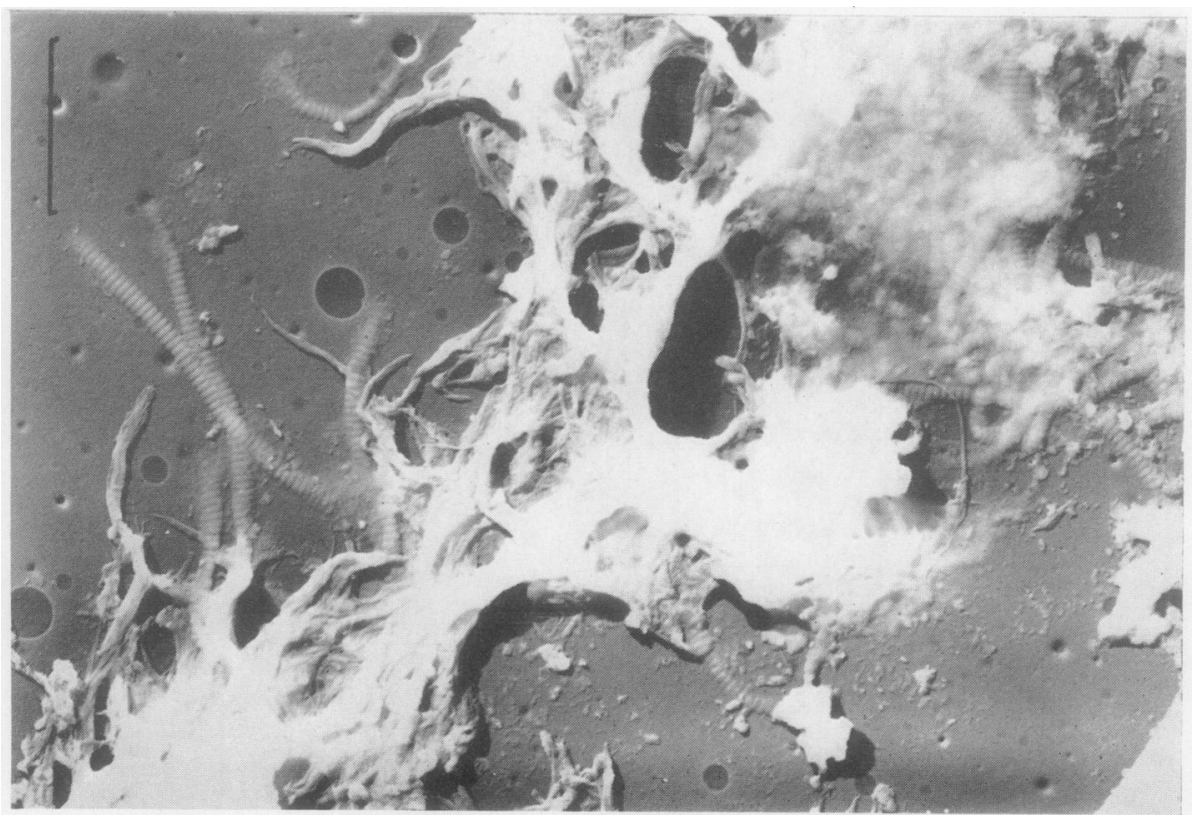


Effect of Borate Buffer ( $p H$ 8.8) for 24 hrs at $37^{\circ} C$. (Tables I and II: Figs 18-25). -The usual increase in amorphous material and dense bits was found in all substrates, being most marked in Groups I and III. A significant increase in "elastin" counts was seen in all the control substrates (with the exception of D12 owing to the gross increase after heat alone for $24 \mathrm{hrs}$ ), being of moderate degree and accompanied by a moderate transformation picture. However, in the 56-year-old adult, there was a slight increase in skin-type only and no transformation picture. Both the 20- and 52-yearold substrates in Group III gave a moderate increase in skin-type and TS with a moderate transformation picture. In contrast, none of Group II had "elastin" counts significantly raised above that which could be accounted for by heat alone. The markedly different responses to alkali by substrates of the same age but belonging to different groups, is illustrated in Figs 18-25.

\section{Collagen (Table I)}

The variation in the starting materials has already been described (Figs 1-8). In general, the younger the substrate, the more easily could fairly mild agents induce fibril degeneration, whereas the older substrates remained relatively unaltered. For example, heat alone for $24 \mathrm{hrs}$ caused a small proportion of the infant collagen D12 to exhibit the early stages of degeneration, and the only substrate in Group II to show any collagen alteration after any treatment was the infant D8. The liability of fibril degeneration also varied between the three groups, being most marked in Group III and nearly absent in Group II.

\section{Elastin}

The different variants have been described above under "Terminology", and the effect of treatment is shown in Table I. The examples of the so-called transformation structures illustrated in Figs 26-35 underline the wide range of variants seen, and Figs 36 and 37 show small areas of the almost continuous transformation picture found in the substrate from the infant (D12) after treatment either with phthalate buffer alone or with periodate in buffer.

\section{Amorphous Material and Dense Bits}

These were plentiful in the younger subjects of Group I and scarcer in the adults. They were strikingly absent in Group II. Incubation with alkaline buffer produced an increase in all substrates, being least noticeable in Group II.

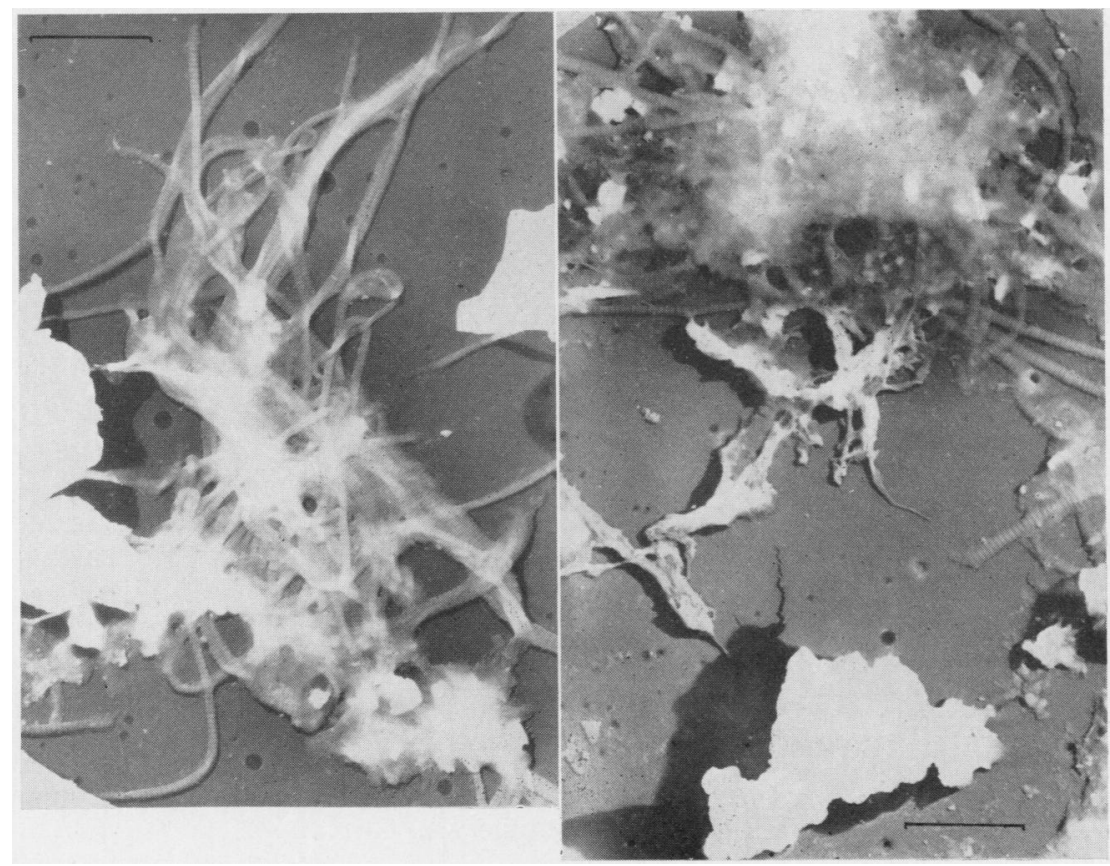

Figs 18 and 19.-Effect of incubation in borate buffer (pH 8.8) for $24 \mathrm{hrs}$ at $37^{\circ} \mathrm{C}$. The collagenaseresistant substrate from the infant (D8) illustrated in Fig. 18 was practically unaltered, whereas the control substrate from the infant (D12) illustrated in Fig. 19 produced a transformation picture. There was an increase in amorphous material and dense bits in both, but this was less marked in D8. 


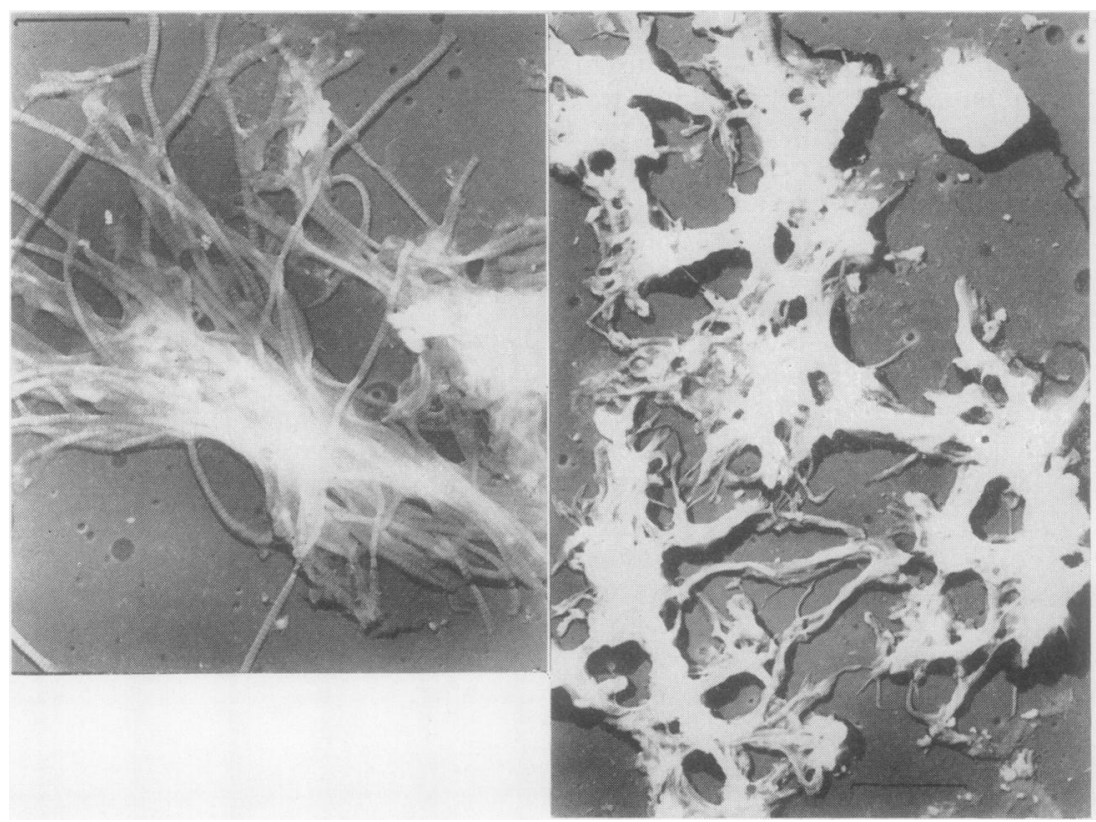

Figs 20 and 21.-Effect of incubation in borate buffer (pH 8.8) for $24 \mathrm{hrs}$ at $37^{\circ} \mathrm{C}$. The $9 \frac{1}{2}$-year-old collagenase-resistant substrate (D9) remained unaltered (Fig. 20), whereas the 9-year-old control (D13) produced a transformation picture. Fig. 21 illustrates part of a sheet of "elastin networks".

\section{Fine Thread-like Structures}

These were described by Keech and others, 1956. They were only found in very small numbers throughout this study, being virtually absent in Group II. Alkaline buffer produced an increase in most of the substrates in Groups I and III.

\section{Manufactured Networks (MN)}

Small and medium-sized structures closely resembling the MN described previously (Keech and others, 1956) were occasionally seen throughout the present study. They numbered one to twenty for each substrate (i.e. per 8-11,000 fields), and there was no correlation with either age, treatment, or "elastin" increase. However, though present throughout Groups I and III, they were only found in two of the youngest substrates in Group II.

\section{Discussion}

Several points arise out of the electron microscope part of this study (Table III):

(1) Treatment of the substrates in water at $37^{\circ} \mathrm{C}$. could produce an increase of up to two or three times the amount of skin-type "elastin" at $24 \mathrm{hrs}$ (Tables I and II). This was associated with relatively unaltered collagen fibrils and did not con- stitute a transformation picture (the exception of D12 has already been mentioned). This finding confirms previous work (Keech and Reed, 1957) on fresh whole dermis, where such an increase was found in all age groups after prolonged incubation, in either water or normal saline, at or below body temperature. This increase was allowed for in estimating the effects of the various reagents, as explained in Table II. However, there was a group difference, Group II showing the least and Group III the greatest responses.

(2) The response to treatment with all the reagents used was dependent on age. The decrease in collagen breakdown as age increased paralleled the quantitative increase in "elastin" recorded in Groups I and III. This lessening reactivity to chemical agents with advancing years is reminiscent of the similar response obtained from identical substrates after incubation with collagenase (Keech, 1954a). However, Group II did not react to either collagenase or to alkali, suggesting that the enzyme may attack similar linkages within the collagen molecule.

(3) This age-dependent response was associated with an age-difference in the collagen fibrils themselves, both in the starting materials within the 


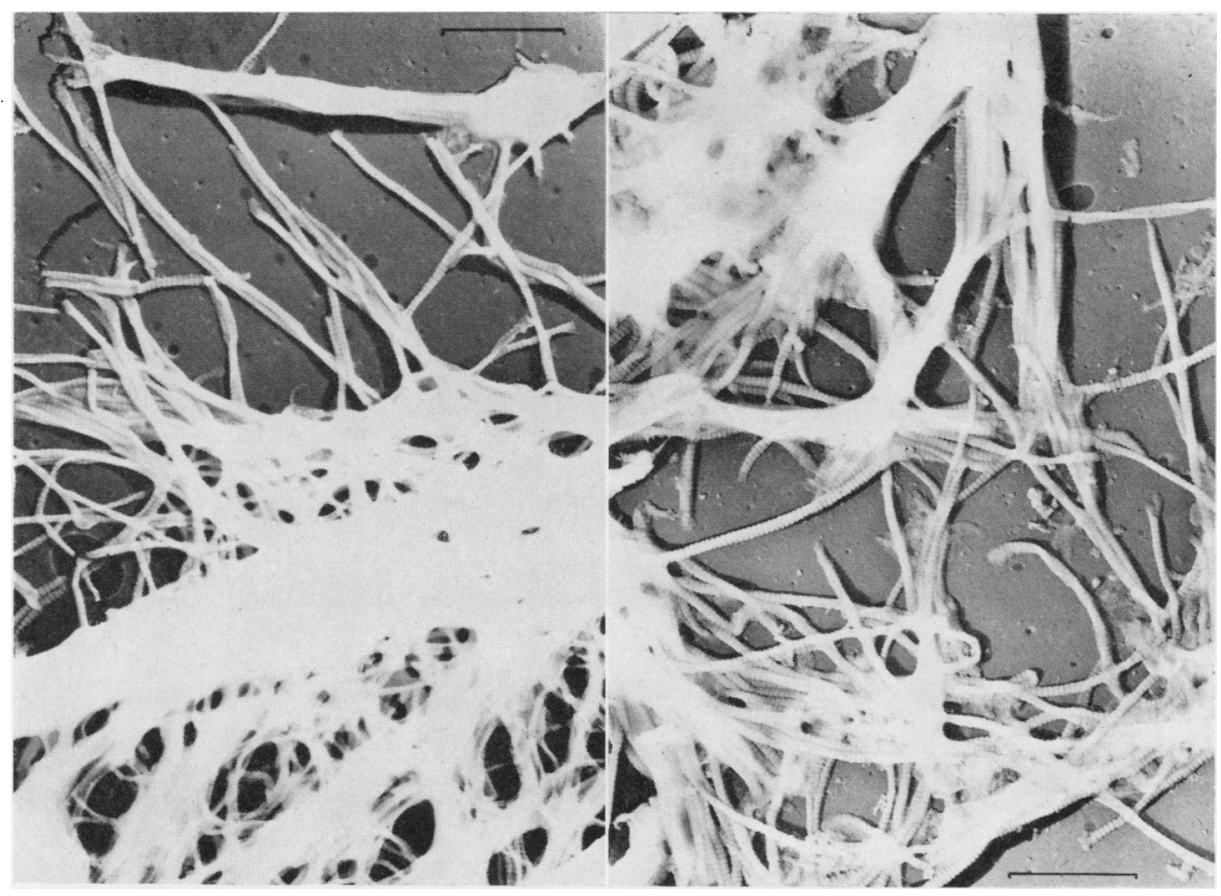

Figs 22 and 23 show the unaltered appearances of the 13-year-old (D10) and 18-year-old (D4) collagenaseresistant substrates respectively.

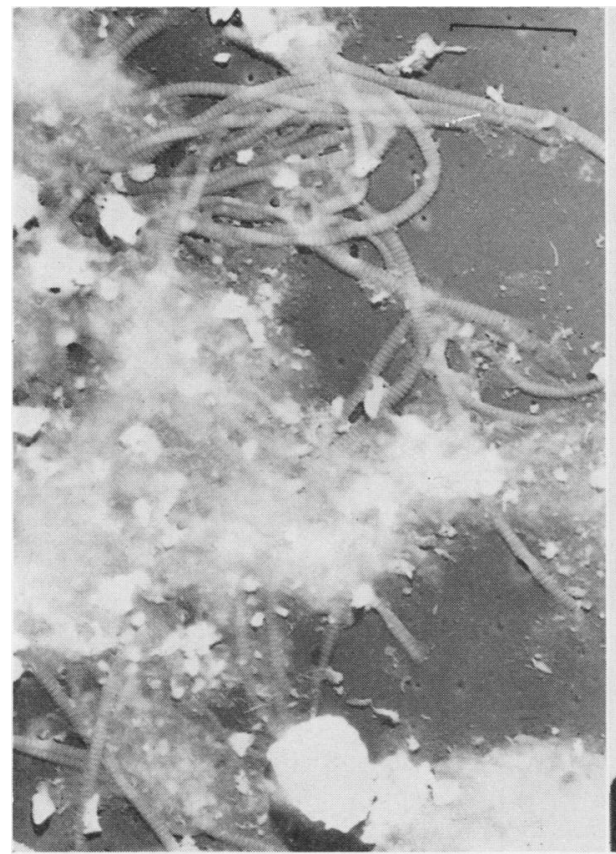

Fig. 24 demonstrates the degenerate appearance of the 19-year-old control collagen (D14) with an increase in amorphous material and dense bits.

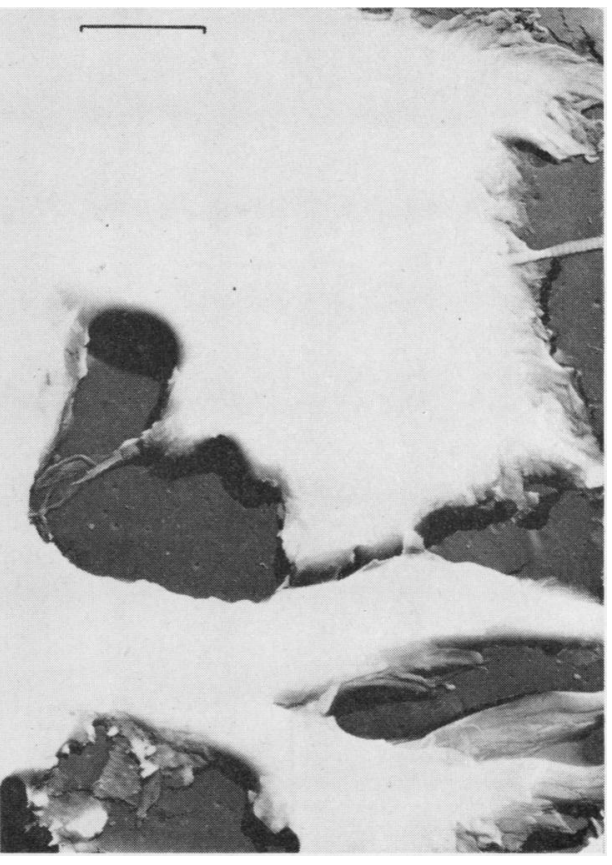

Fig. 25 illustrates part of one of the many large transformation structures found in the 20-year-old substrate exhibiting excessive collagenase digestion (D6).

Figs 22 to 25.-Effect of incubation in borate buffer (pH 8.8) for $24 \mathrm{hrs}$ at $37^{\circ} \mathrm{C}$. 


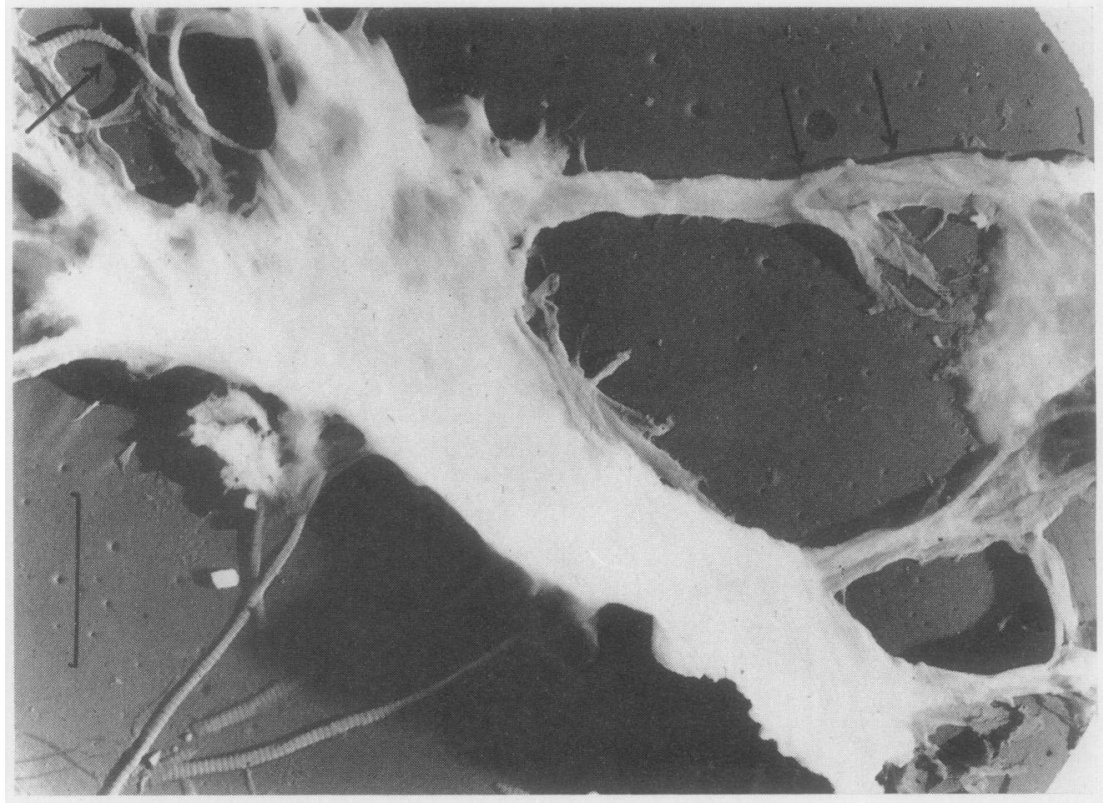

Fig. 26.-Transformation structure (TS) from the 51-year-old collagenase-resistant substrate (D3) after heating in water for $24 \mathrm{hrs}$ at $37^{\circ} \mathrm{C}$. The two arrows indicate a striated collagen fibril which apparently changes to "elastin". The single arrow demonstrates part of a collagen fibril under tension, as illustrated and described previously (Keech and others, 1956).

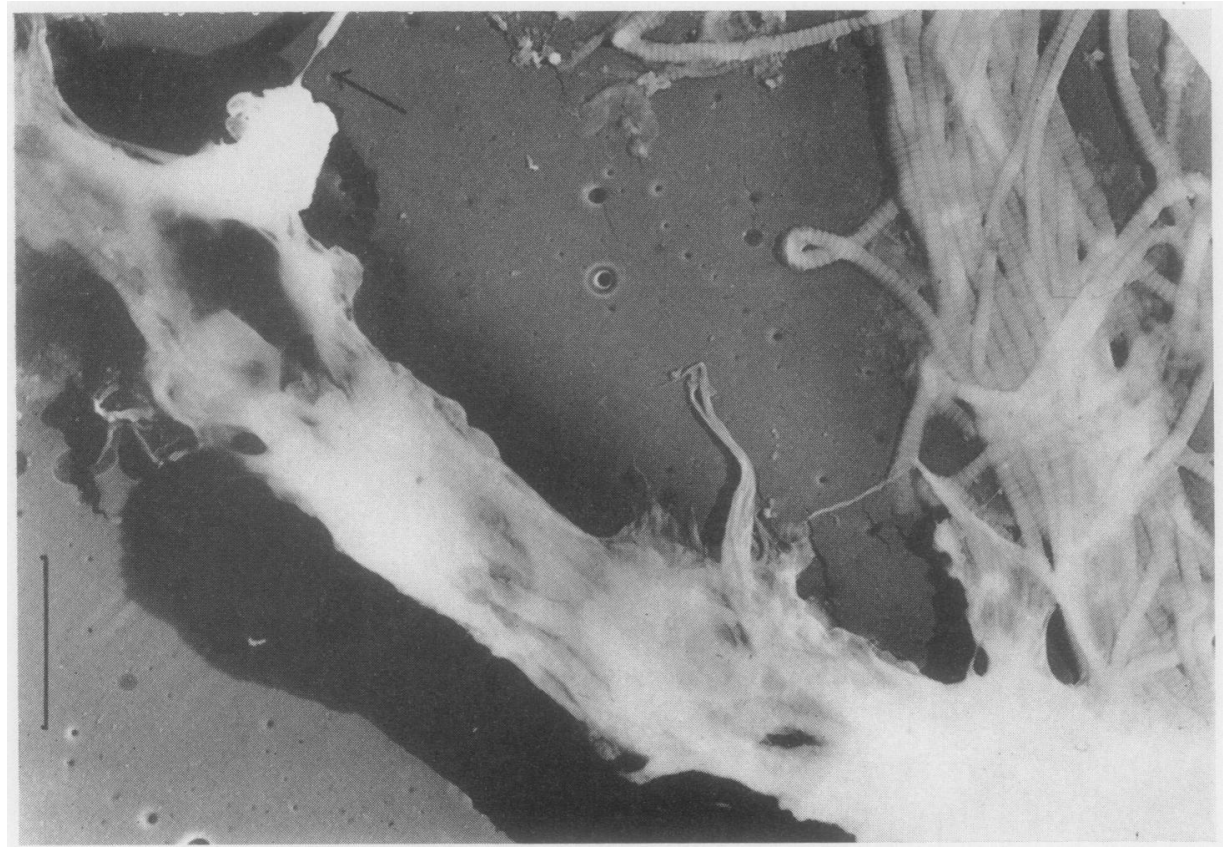

Fig. 27.-Transformation structure (TS) from the 52-year-old substrate exhibiting excessive collagenase digestion (D7), after incubation in phthalate buffer $\left(\mathrm{pH} \mathrm{5.0)}\right.$ for $1 \frac{1}{2} \mathrm{hrs}$ at $37^{\circ} \mathrm{C}$. The thick, elastin-like structure splays out into a bundle of collagen fibrils at the upper left corner of the picture. The arrow indicates part of a collagen fibril under tension and raised above the surface of the grid as demonstrated by the direction of the shadow (Keech and others, 1956). 


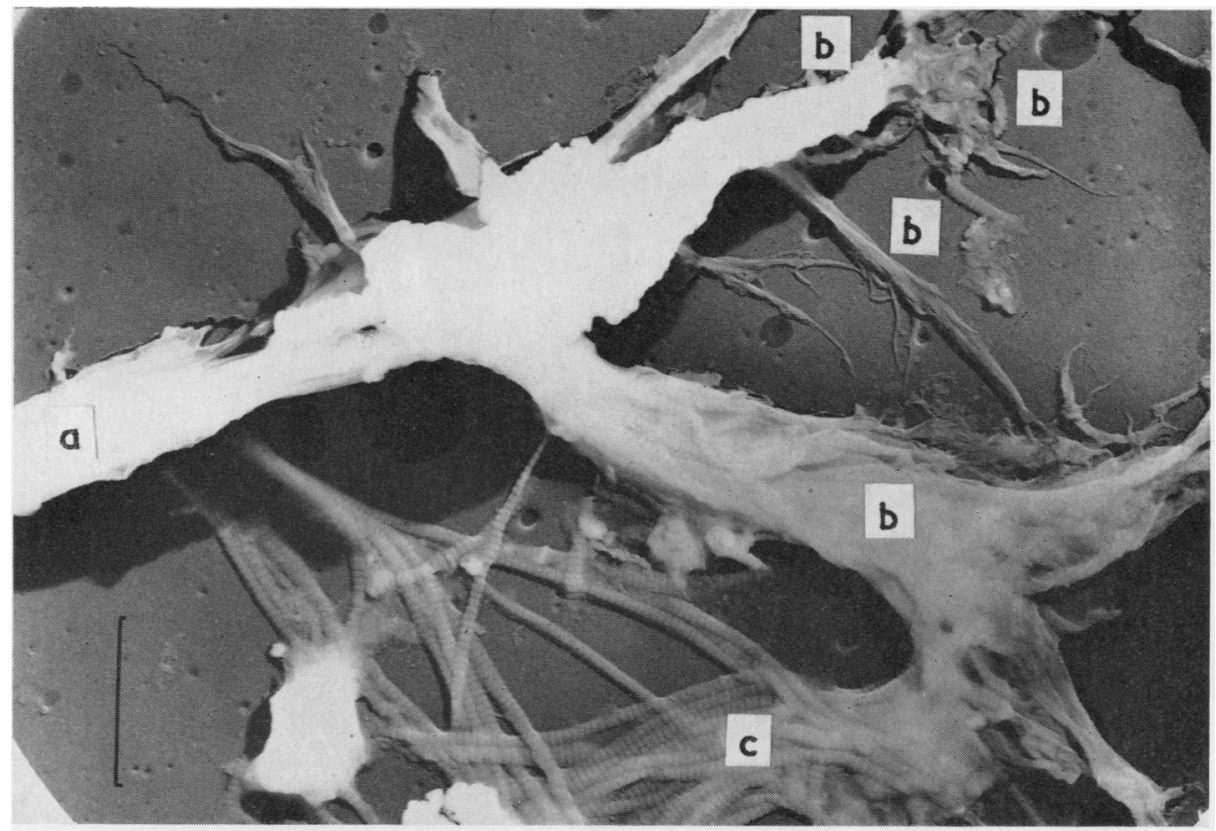

Fig. 28.-Transformation structure (TS) from the 5-year-old collagenase-resistant substrate (D11) after heating in water for $24 \mathrm{hrs}$ at $37^{\circ} \mathrm{C}$. The dense bundle (a) splays out into several areas typical of "elastin" (b-b) finally merging into a bundle of collagen fibrils (c).

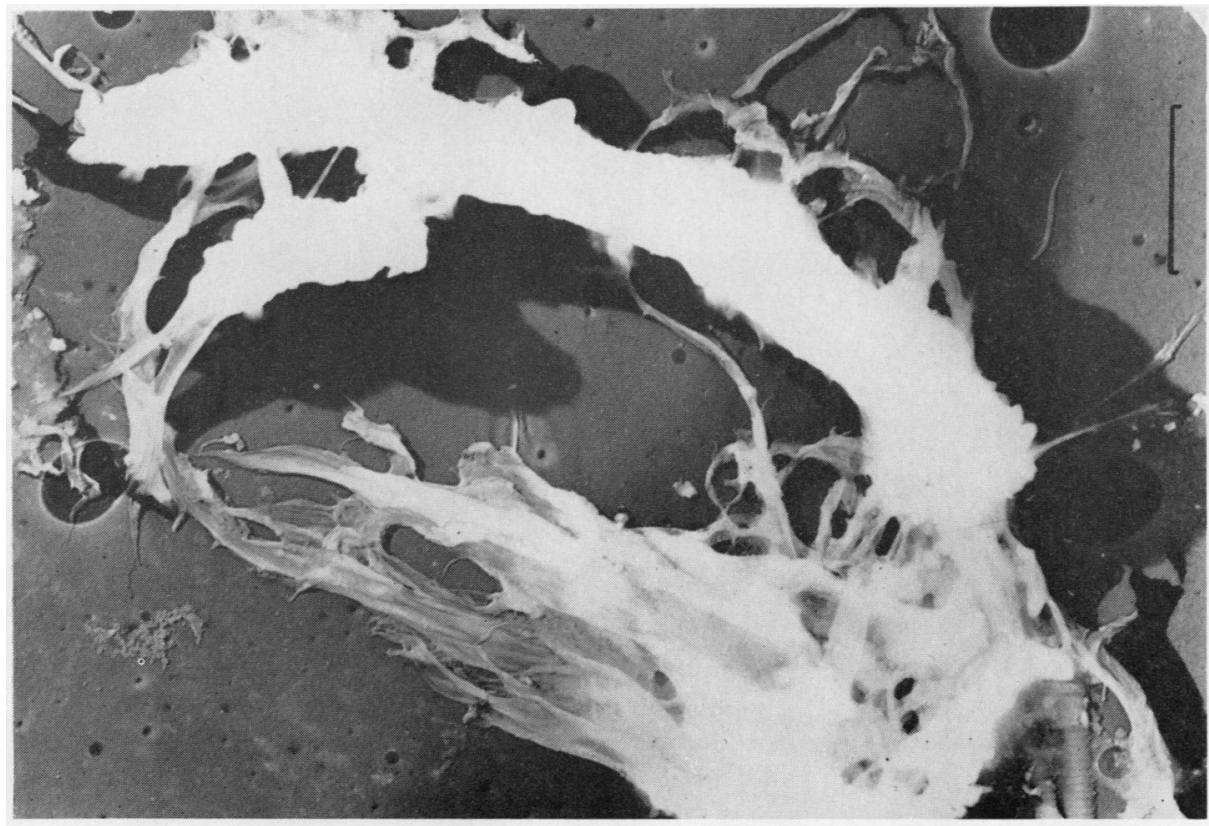

Fig. 29. - Transformation structure (TS) from the 19-year-old control starting material (D14). Each end of the dense bundle splays out into elastin-like material. 


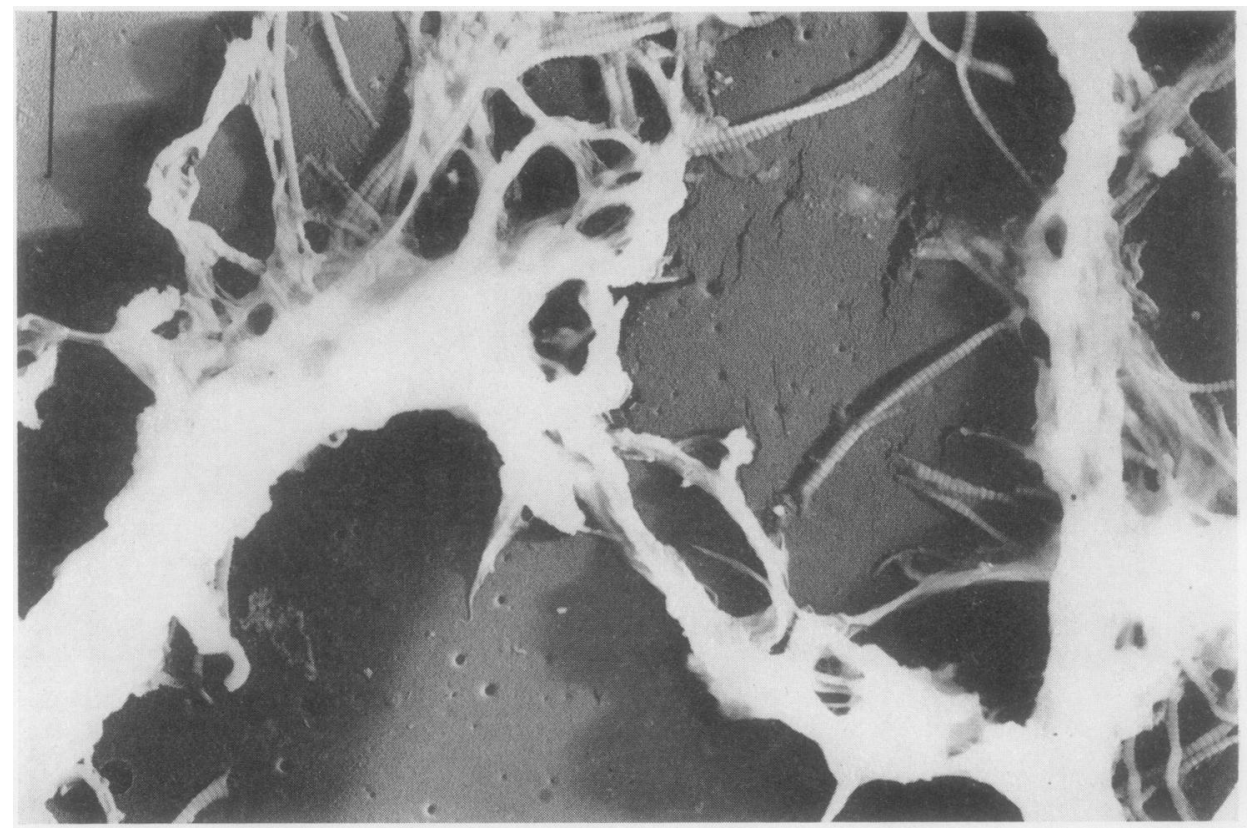

Fig. 30.-Part of a large transformation structure (TS) from the 51-year-old collagenase-resistant substrate (D3) after incubation with periodate in phthalate buffer $(\mathrm{pH} 5.0)$ for $1 \frac{1}{2} \mathrm{hrs}$ at $37^{\circ} \mathrm{C}$. The elastin-like material is intimately associated with the striated collagen fibrils.

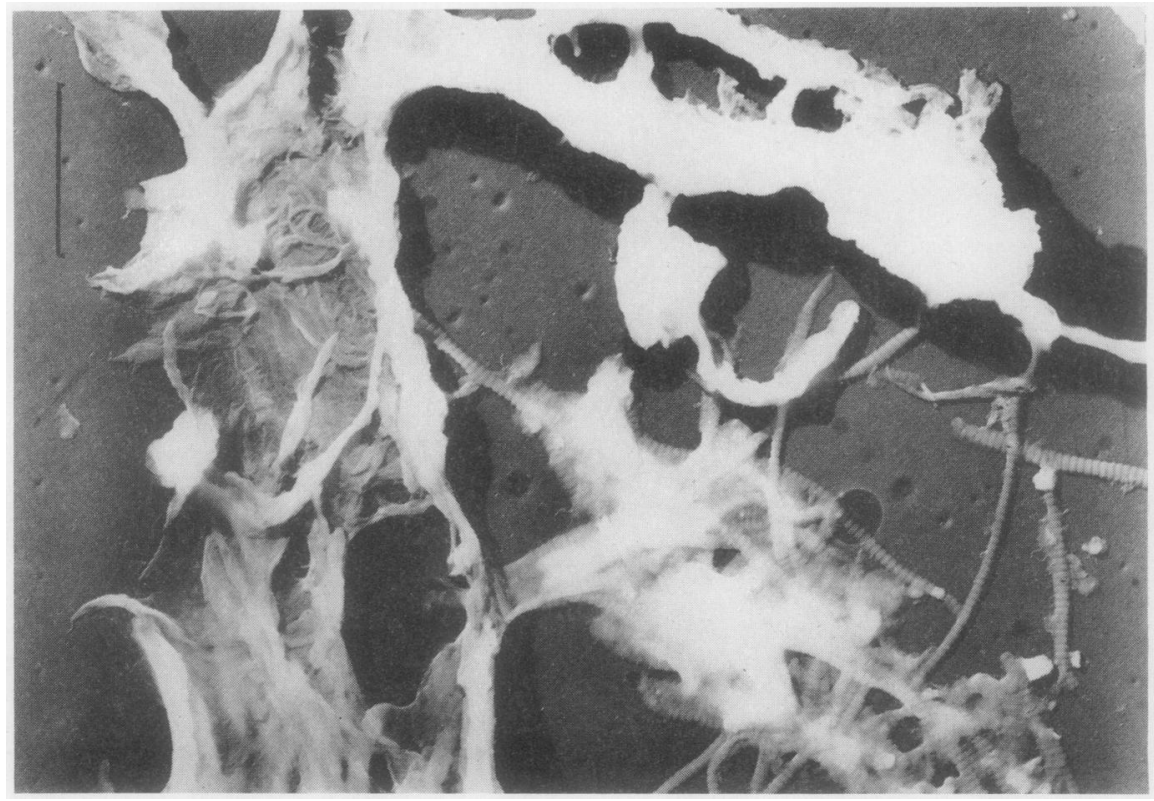

Fig. 31.-Part of a large transformation structure (TS) from the $9 \frac{1}{2}$-year-old collagenase-resistant substrate (D9) after heating in water for $24 \mathrm{hrs}$ at $37^{\circ} \mathrm{C}$. Each end of the dense bundle splays out into "elastin".

control group and between groups (see Table III). The appearance of the fibrils reflected the reactivity of each particular substrate: when they showed evidence of degeneration, the "elastin" counts were increased and transformation pictures were found. On the other hand, the unaltered fibrils in Group II 


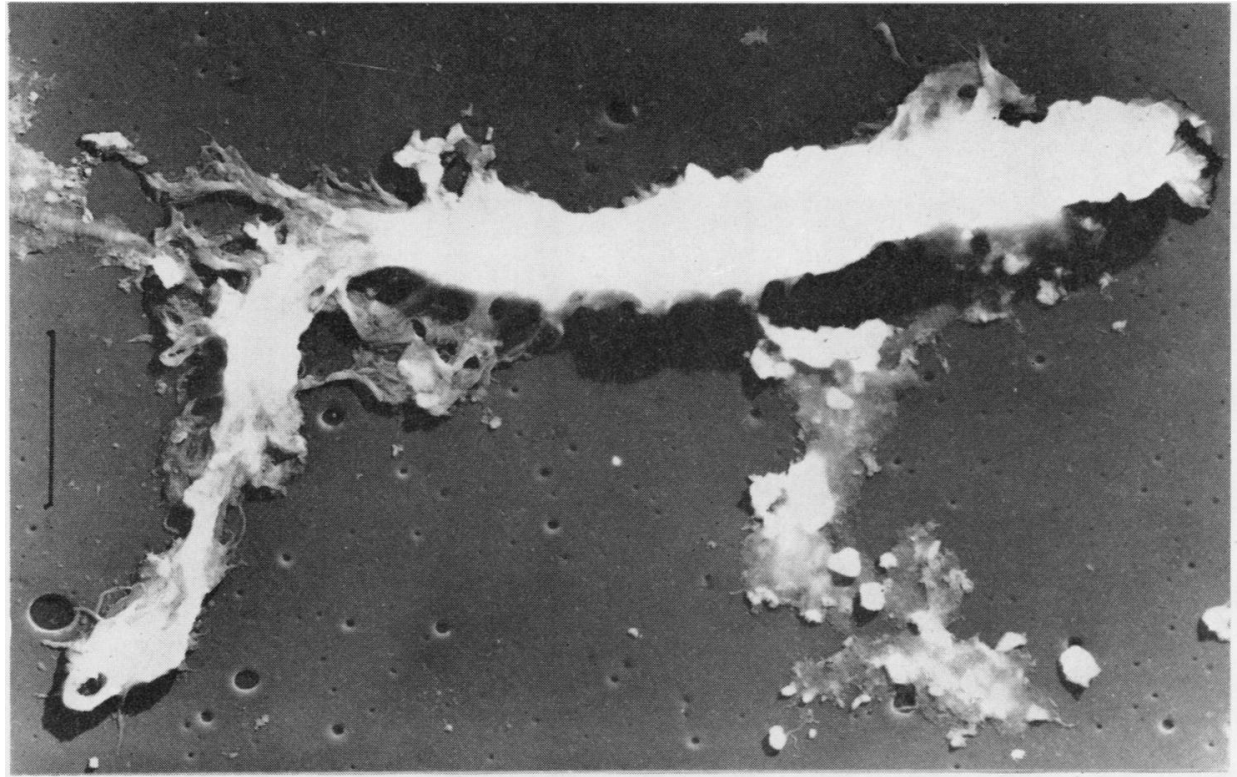

Fig. 32.-A small transformation structure (TS) from the 9-year-old control substrate (D13) after heating in water for $1 \frac{1}{2} \mathrm{hrs}$ at $37^{\circ} \mathrm{C}$. The smaller quantity of electron-opaque material at one end allows the underlying elastinlike nature of the structure to be revealed.

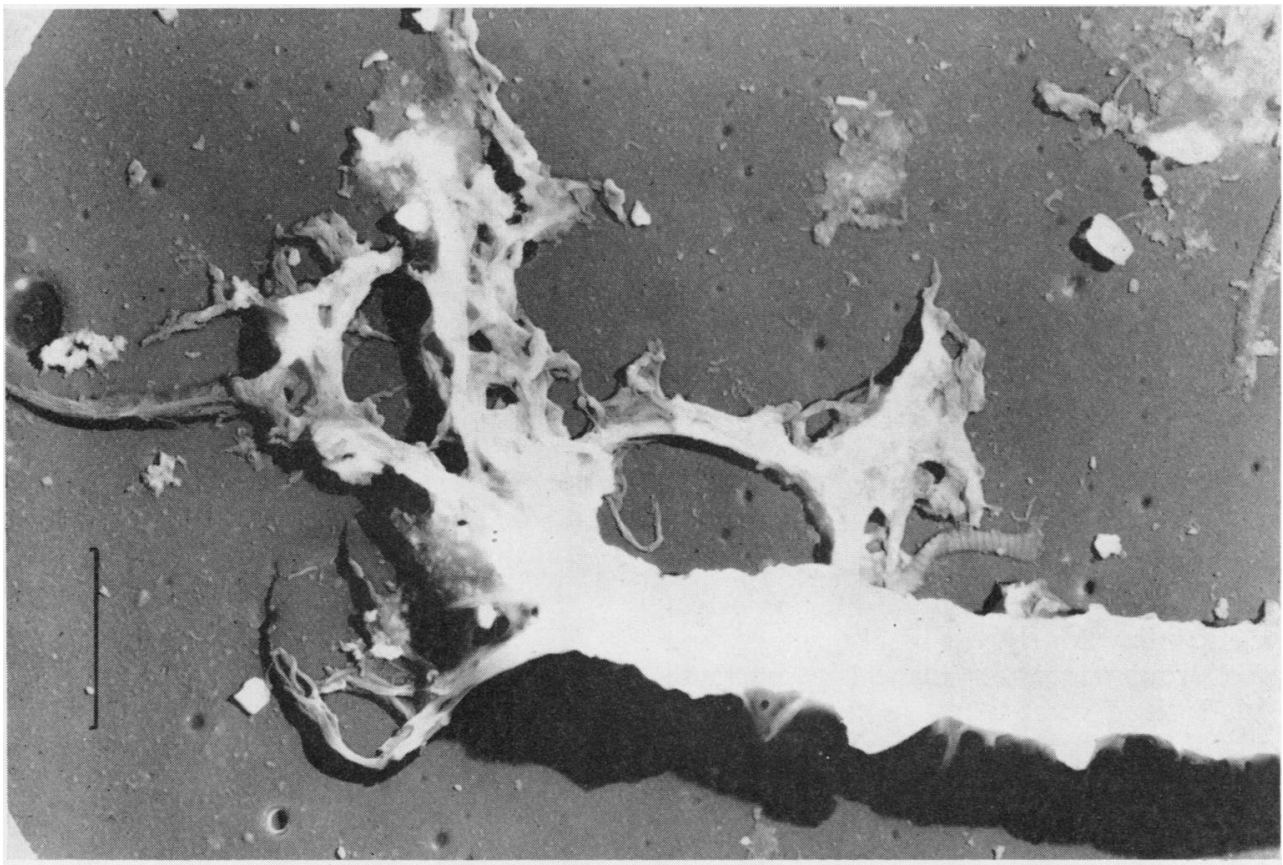

Fig. 33.-Transformation structure (TS) from the same substrate as Fig. 32 after incubation in phthalate buffer (pH 5.0 ) for $3 \mathrm{hrs}$ at $37^{\circ} \mathrm{C}$. Part of a long, dense bundle terminating as "elastin".

correlated with the lack of response which characterized this particular group.

(4) The same reagents had different effects on different groups. The response of the three groups showed a striking similarity to their known reactivity towards collagenase: the collagenase-resistant sub- 


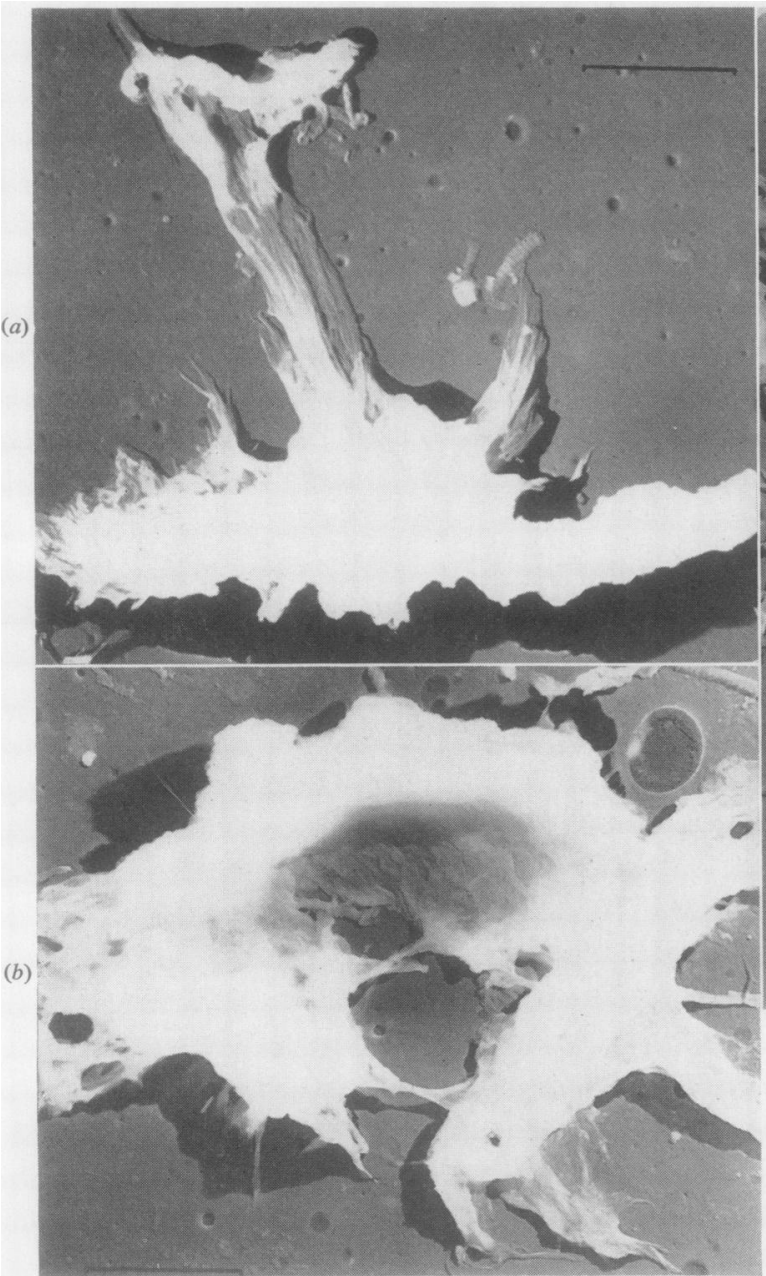

Fig. 34(a, b). - Two small transformation structures (TS) demonstrating the appearance of elastin-like material where the dense coating of amorphous material is reduced in amount. Numerous examples were seen throughout this investigation.

strates were relatively inert, those exhibiting excessive enzyme digestion were highly active, and the control group was intermediate between these two. This is demonstrated by the total "elastin" counts recorded at the foot of Table I. The count from the five substrates in the control group (13, 446) was nearly $3 \frac{1}{2}$ times that for the six collagenase-resistant substrates $(4,006)$. In contrast, the two substrates exhibiting excessive digestion by collagenase gave a slightly higher total $(4,124)$ than the six indigestible derma.

(5) A 3-hr incubation with phthalate buffer alone $(\mathrm{pH} 5 \cdot 0)$ gave a greater response in all the groups

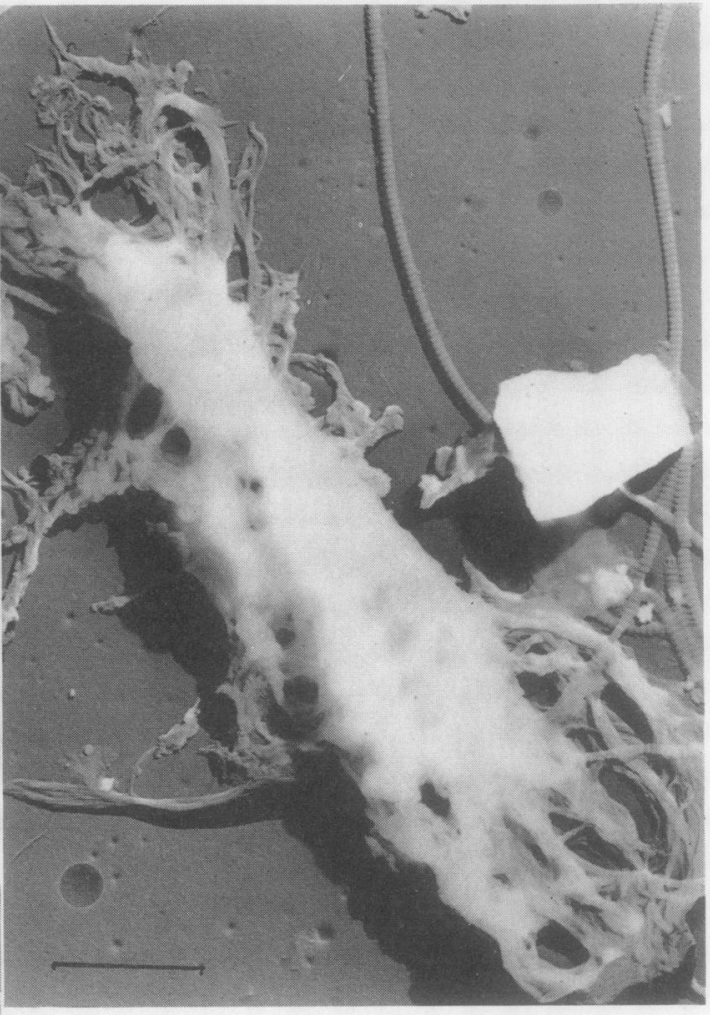

Fig. 35.-Transformation structure (TS) from the 56-year-old control substrate (D15) after incubation with periodate in phthalate buffer $\left(\mathrm{pH} \mathrm{5.0)}\right.$ for $3 \mathrm{hrs}$ at $37^{\circ} \mathrm{C}$. Most of the dense bundle can be visualized as "elastin".

than either periodate in phthalate buffer or borate buffer $(\mathrm{pH} 8.8)$ for 24 hrs at $37^{\circ}$ C. These experiments in buffer alone were the control series for the periodate studies, and periodate was one of the first reagents described which apparently transforms collagen into elastin-like structures (Burton and others, 1955). However, the detailed scrutiny and exhaustive counting undertaken in the present investigation revealed that, though the periodate experiments did increase the "elastin" counts and produced a transformation picture, the buffer solutions alone gave a greater response in all cases. It is also noteworthy that this response occurred after only 3 hours' incubation, and that both periodate and phthalate buffer alone produced higher counts and more transformation pictures than the longer, 24-hr incubation with alkali. In addition, the phthalate buffer alone evoked a response even in two of the youngest subjects (D8 and D9), yet both periodate and alkali were 


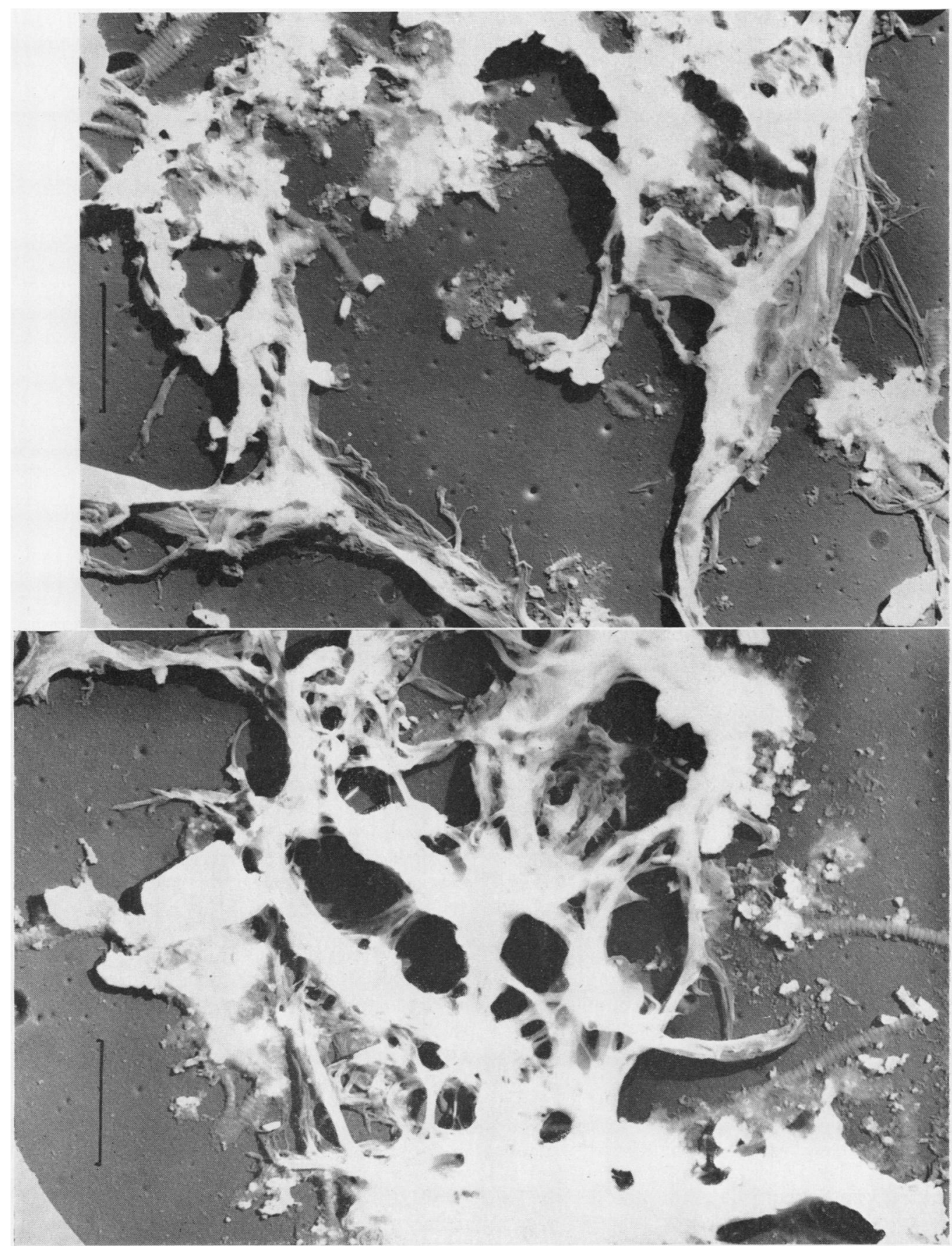

Figs 36 and 37.-Incubation of the control substrate from the infant (D12) for 3 hrs at $37^{\circ} \mathrm{C}$. with periodate in phthalate buffer (Fig. 36) and in phthalate buffer (pH 5-0) alone (Fig. 37). These illustrate small areas from the almost continuous transformation picture seen after each of these treatments. 
without effect. These as yet unexplained phenomena merit further study. It is possible that the addition of the 1 per cent periodate solution to the phthalate buffer produced a dilution effect or an alteration in ionic strength which decreased the ability of the reagent to break down collagen. Unfortunately insufficient dermal substrate remained to investigate this matter in detail.

The paucity of the fine thread-like structures (Table I) following the action of all the reagents used in this study is in conformity with previous work (Keech and others, 1956) which demonstrated an increase in numbers as the $\mathrm{pH}$ value rose above 7.0. Most of the present experiments were conducted at $\mathrm{pH} 5.0$ and 5.6 , but incubation with borate buffer ( $\mathrm{pH} 8 \cdot 8)$ produced an increase in most of the substrates in Groups I and III. The appearance of structures closely resembling the manufactured networks (MN) described previously, show that they can occur at $37^{\circ} \mathrm{C}$. although they were far less in comparison with the numbers seen after heating above body temperature, treatment with acetic acid, etc., as already reported (Keech and others, 1956). In the present investigation, only 65 of these manufactured networks were seen in the process of scanning a minimum of 120,000 fields. Their occurrence was sporadic, and bore no apparent relationship to age, treatment, or increase in "elastin".

It must be remembered that the starting materials used throughout comprised human dermis that had been "purified" by the method of Neuman (1949a, b) as shortened by Keech (1954a). This process involves prolonged extraction at $4^{\circ} \mathrm{C}$. with 10 per cent. $\mathrm{NaCl}$ followed by $\mathrm{N} / 15 \mathrm{Na}_{2} \mathrm{HPO}_{4}$, to remove mucoproteins and interfibrillar material. It is unlikely that this would affect the original natural elastin, which is present in small quantities in all the starting materials. However, although Neuman claims that this procedure does not denature or alter the properties of collagen, recent work demonstrating the apparent transformation of collagen to elastin-like structures by alkali (Burton and others, 1955; Hall and others, 1955) throws doubt on this method of preparation. However, whatever the nature of the substrate after purification, does not invalidate the comparisons made in this study.

The lack of response to incubation with borate buffer ( $\mathrm{pH} 8.8)$ exhibited by all the collagenaseresistant substrates, both biochemically (vide infra) and under the electron microscope, provides a clue to the uniform morphology of all the starting materials in this group (Tables I and III). The alkali used in Neuman's procedure may have removed the interfibrillar material without altering the fibrils, thus accounting for the clean appearance of the collagen and the lack of amorphous material and dense bits (which are presumably derived from the products of collagen breakdown). This group's resistance to breakdown correlated with a lack of transformation into "elastin". However, in the two inert substrates in which collagen degeneration was induced by phthalate (D8 and D9 vide supra) the usual conversion to elastin-like material was found. This is in keeping with the hypothesis (Hall and others, 1955) postulating collagen breakdown as a prerequisite for the formation of "elastin" by rearrangement of the collagen components.

The following diagram offers an explanation for the morphological findings as based on our knowledge to date.

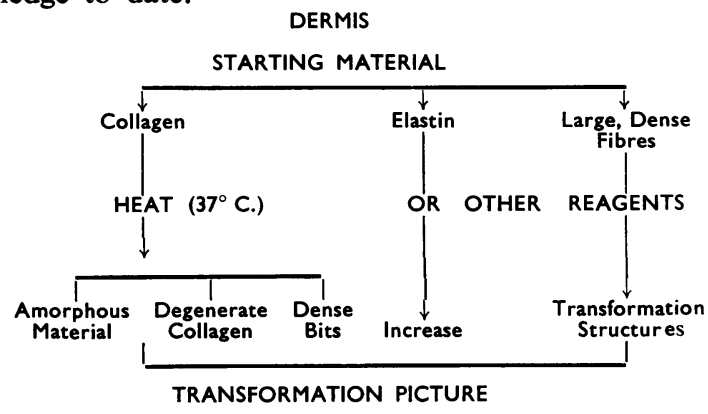

The starting materials of both fresh whole dermis and the "purified" dermis of all age groups contain collagen, a small quantity of naturally-occurring or fully-formed elastin, and large, dense, square-ended fibres. Prolonged heat alone, at or below body temperature, can produce evidence of early collagen degeneration in the substrates from children and young adults (Keech and Reed, 1957), the effect being markedly increased by the addition of reagents such as borate, periodate, or phthalate. Collagen degeneration is associated with an increase in amorphous material and dense bits, which are probably collagen breakdown products.

The amorphous material under the electron microscope may derive from two sources: the breakdown of the collagen fibrils themselves, or the interfibrillar material released from the bundles during the various treatments. It may vary, therefore, in chemical composition according to its origin. Since an increase in skin-type "elastin" only occurs in the presence of some degree of collagen breakdown, these structures could be formed from degraded collagen combined with varying amounts of amorphous material.

Another possible, though not probable, cause of the increase in fully-formed "elastin" would be the progressive fragmentation of the original elastin by 
heat, breaking it up into a larger number of smaller pieces. This seems unlikely, as there was no noticeable decrease in the size of the structures counted after heat alone.

As mentioned above, it has already been reported that the large, dense, square-ended fibres present in all the starting materials are converted into transformation structures (Keech and Reed, 1957). Thus two pathways are postulated for the production of the elastin-like material which constitutes the transformation picture: the products of collagen degeneration combine with varying amounts of amorphous material to give fully-formed "elastin", and the large, dense, fibres give rise to the TS.

Both these pathways can occur after the application of heat alone (depending on the age of the dermis), but the process is greatly enhanced by reagents such as borate, periodate, and phthalate. That these two mechanisms need not necessarily react together or in the same degree, is illustrated in Group II. Heat alone produced a smaller increase in skin-type "elastin" in these collagenaseresistant substrates, but a greater increase in TS when compared with the control group (Table II). This difference in response is thus further evidence of the different reactivities of these two groups of collagen.

The results of biochemical investigations of the same dermal substrates were in general agreement with the electron microscope findings. Protein determinations after incubation with either borate buffer (pH 8.8) or potassium hydrogen phthalate buffer (pH 5.0) revealed a difference between the three groups. The substrates of average collagenase sensitivity gave results similar to those recently reported (Hall, 1956), i.e. a tendency for the amount of protein dissolved by alkali to decrease as the age of the subject increased. In contrast, the two collagenase-resistant substrates showed no significant breakdown by alkaline buffer, whereas the group which exhibited excessive digestion by collagenase gave higher readings than controls of comparable age. Similar results were found after incubation with phthalate buffer.

Chromatography showed that the total amino acid analysis was the same for all the groups, only the substrates in Group III took three times as long to hydrolyse as the others. The hydroxyproline content and shrinkage temperatures have recently been reported in detail (Hall and Reed, 1957). The hydroxyproline levels of all three groups were within the normal (mammalian) range, the values lying between $12 \cdot 3-14 \cdot 3$ per cent. The micro-shrinkage temperatures (Borasky and Nutting, 1949), however, were quite distinct. The collagens in the control group shrank over a range of 62 to $69 \cdot 5^{\circ} \mathrm{C}$., and the collagenase-resistant samples in Group II over a range of 72 to $79 \cdot 5^{\circ} \mathrm{C}$., whilst those in Group III, which were hypersensitive towards collagenase, shrank over the lower temperature range of 60 to $67^{\circ} \mathrm{C}$. Thus, the distinct ranges of thermal shrinkage again reflected a difference between the three groups of collagen. In view of the drawbacks of Neuman's "purification" method already mentioned, no firm chemical explanation is possible. However, the most likely hypothesis is a difference in mucoid between the three groups.

The fact that the fibrils exhibit the morphological characteristics of normal collagen does not preclude a chemical difference. Morphological similarity does not necessarily mean chemical identity, as was recently demonstrated by Solomons and Irving (1956). They found that the availability of hydroxylysine and lysine polar side-chains was significantly greater in human dentin than in ox-hide collagen, and that this availability probably played a part in the combination of mineral material with the protein matrix of human dentin. This protein matrix has been shown under the light microscope (Widdowson, 1952) and under the electron microscope (Scott and Wyckoff, 1950; Yasuzumi and Obata, 1955) to consist of collagen morphologically identical with that found in human and animal skin. Thus, the collagenase-resistant collagens investigated in the present study may contain linkages which are either inaccessible to the action of collagenase and alkali, or, by some configurational variation from the normal collagen, are inaccessible to these two reagents. In the two collagenase-resistant substrates, which were mildly attacked by phthalate, one must assume that the linkages concerned in this type of reaction differ from those susceptible to collagenase and alkali.

The importance of the reactivity of collagen to collagenase has recently been shown by Ziffren and Hosie (1955), who demonstrated collagenase activity in canine pancreatic juice. Previous work (Keech, 1954b) suggested the presence of some substance capable of altering collagen in human dermis of all age groups. As mentioned at the beginning of this paper, rash-bearing and non-rash-bearing skin from a case of dermatomyositis differed in sensitivity towards collagenase. The answer to this riddle may be the key to the cause of so-called "collagen disease".

\section{Summary}

Further investigations were undertaken on six of the collagenase-resistant human dermal substrates and the two exhibiting excessive digestion by collagenase previously described by Keech (1955). 
These were compared with five substrates showing average collagenase sensitivity.

Under the electron microscope, a significant increase in elastin-like structures was produced by phthalate buffer, periodate, and alkaline buffer, the degree of response depending on the age of the subject. The results paralleled the sensitivity of the substrate towards collagenase, the resistant group remaining unattacked by alkali and periodate, and only two of the six being mildly attacked by phthalate. In the remaining cases, phthalate buffer alone proved to be a more potent reagent for the apparent transformation of collagen to elastin-like structures than either periodate or alkali. Treatment in water at $37^{\circ} \mathrm{C}$. produced a slight increase in "elastin", which was allowed for when the effect of incubation with chemical reagents was assessed. Only the latter gave a true transformation picture to "elastin". The tabulated results are based on the careful scrutiny of a minimum of 120,000 microscopic fields, and a total of 21,576 elastin structures were counted.

Biochemical studies confirmed the electron microscopic findings and the shrinkage temperature also reflected the different reactivity of these three groups of collagen.

It is a pleasure to thank Professor R. E. Tunbridge, O.B.E., for his sustained encouragement throughout this work, Dr. D. A. Hall and Mr. J. W. Czerkawski for performing the biochemical estimations, and Mr. A. Gill for the shrinkage temperature studies.

\section{REFERENCES}

Borasky, R., and Nutting, G. C. (1949). J. Amer. Leather Chem. Ass., XLIV, 830 .

Burton, D., Hall, D. A., Keech, M. K., Reed, R., Saxl, H., Tunbridge R. E., and Wood, M. J.'(1955). Nature (Lond.), 176, 966.

Hall, D. A. (1956). "Experimental Alternsforschung Symposium, Basel", p. 19-27. Birkhaüse Verlag, Basel.

, Keech, M. K., Reed, R., Saxl, H., Tunbridge, R. E., and Wood, M. J. (1955). J. Gerontol., 10, 388

Keect and Reed, R. (1957). Nature (Lond.), 180, 243.

Keech, M. K. (1954a). Yale J. Biol. Med., 26, 295.

Keech, (1954b). Ibid., 26, 527.

(1955). Ann, rheum. Dis., 14, 19.

, and Reed R. (1957). Ibid., 16, 198.

—, and Reed R. (1957). Ibid., 16, 198.

Neuman, R. E. (1949a). "A Comparative Study of Collagen and Elastin". Ph.D. Thesis, University of Cincinnati. Elastin". Ph.D. Thesis, University
(1949b). Arch. Biochem., 24, 289.

Scott, D. B., and Wyckoff, R. W. G. (1950). J. dent. Res., 29, 556

Solomons, C. C., and Irving, J. T. (1956). Nature (Lond.), 178, 548.

Widdowson. T. W. (1952). "Special or Dental Anatomy and Physiology and Dental Histology", 8th ed., vol. I, pp. 179-83. Staples Press, London.

Yasuzumi, G., and Obata, Y. (1955). J. dent. Res., 34, 808

Ziffren, S. E., and Hosie. R. T. (1955). Proc. Soc. exp. Biol. (N.Y.), 90,650 .

Transformation du collagène en "élastine" dans les collagènes dermiques avec sensibilité variable à la collagénase

RÉSUMÉ

On procéda à de plus amples recherches sur six substrata collagénase-résistants des dermes humains et sur les deux qui présentaient une digestion excessive par la collagénase, précédemment décrits par Keech (1955). On les compara à cinq substrata présentant une sensibilité moyenne à la collagénase.

Sous le microscope électronique, une augmentation significative des structures ressemblant à l'élastine se produisait par un tampon de phthalate, de périodate et un tampon alcalin, l'intensité de la réaction dépendant de l'âge du sujet. Les résultats étaient parallèles à la sensibilité du substratum à la collagénase, le groupe résistant n'étant pas attaqué par l'alcali et périodate, et seulement deux des six étant légèrement attaqués par le phthalate. Dans les cas restants, le tampon de phthalate seul s'est révélé un réactif plus puissant, pour la transformation apparente du collagène en structures semblables à l'élastine, que le périodate ou l'alcali. Le traitement par l'eau à $37^{\circ} \mathrm{C}$. produisait une légère augmentation d"“élastine"; on en tenait compte en évaluant l'effet de l'incubation avec des réactifs chimiques. Seule cette dernière méthode donnait un vrai tableau de la transformation en "élastine". Les résultats catalogués sont basés sur l'examen soigné d'un minimum de 120.000 champs microscopiques et un total de 21.576 structures d'élastine a été compté.

Des études biochimiques ont confirmé les observations au microscope électronique et la température de contraction a refleté aussi la réactivité différente de ces trois groupes de collagène.

Transformación del colageno en "elastina" en los colagenos cutáneos con sensibilidad variable a la colagenasa

SUMARIO

Se efectuaron investigaciones ulteriores sobre seis de los substratos de la piel humana resistentes a la colagenasa y sobre los dos que habían presentado una digestión excesiva por la colagenasa, anteriormente descritos por Keech (1955). Se los comparó a cinco substratos presentando una sensibilidad media a la colagenasa.

Bajo el microscopio electrónico, un aumento significativo de estructuras parecidas a elastina se produjo por un tapón de ftalato, de periodato y por un tapón alcalino, la intensidad de la reacción dependiendo de la edad del sujeto. Los resultados fueron paralelos a la sensibilidad del substrato a la colagenasa, el grupo resistente no siendo atacado por el alcali o el periodato, y sólo dos de los seis siendo ligeramente atacados por el ftalato. En los demás casos, el tapón de ftalato solo se reveló un reactivo más fuerte, para la transformación aparente del colageno en estructuras parecidas a la elastina, que el periodato o el alcali. El tratamiento por el agua a $37^{\circ}$ C. producía un ligero aumento de "elastina"; esto fué tomado en cuenta en la valoración del efecto de la incubación con reactivos químicos. Tan sólo este método daba el cuadro auténtico de la transformación en "elastina". Los resultados enumerados se basan en la investigación cuidadosa de un mínimo de 120.000 campos microscópicos y un total de 21.576 estructuras de elastina fué contado.

Estudios bioquímicos confirmaron las observaciones al microscopio electrónico y la temperatura de contracción también reflejó la reactividad diferente de estos tres grupos de colageno. 